\title{
Article \\ Modelling Key Performance Indicators in a Gamified Waste Management Tool
}

\author{
Georgios Pappas ${ }^{1,2,3, *(\mathbb{D})}$, Iliana Papamichael ${ }^{4} \mathbb{D}$, Antonis Zorpas ${ }^{4}\left(\mathbb{D}\right.$, Joshua E. Siegel ${ }^{5}\left(\mathbb{D}\right.$, Jacob Rutkowski ${ }^{5} \mathbb{D}$ \\ and Konstantinos Politopoulos 2 (D)
}

1 Department of Electrical and Computer Engineering, Michigan State University, East Lansing, MI 48824, USA

2 Department of Electrical and Computer Engineering, National Technical University of Athens, Zografou, 15780 Athens, Greece; policent@central.ntua.gr

3 Laboratory of Educational Material and Methodology, Open University of Cyprus, Latsia, Nicosia 2220, Cyprus

4 Laboratory of Chemical Engineering and Engineering Sustainability, Faculty of Pure and Applied Sciences, Open University of Cyprus, P.O.Box 12794, Latsia, Nicosia 2252, Cyprus; iliana.papamichael@st.ouc.ac.cy (I.P.); antonis.zorpas@ouc.ac.cy (A.Z.)

5 Department of Computer Science and Engineering, Michigan State University, East Lansing, MI 48824, USA; jsiegel@msu.edu (J.E.S.); rutkow72@msu.edu (J.R.)

* Correspondence: geopap1987@hotmail.com

check for updates

Citation: Pappas, G.; Papamichael, I.; Zorpas, A.; Siegel, J.E.; Rutkowski, J.; Politopoulos, K. Modelling Key Performance Indicators in a Gamified Waste Management Tool. Modelling 2022, 3, 27-53. https://doi.org/ 10.3390/modelling3010003

Received: 25 October 2021

Accepted: 17 December 2021

Published: 24 December 2021

Publisher's Note: MDPI stays neutral with regard to jurisdictional claims in published maps and institutional affiliations.

Copyright: (c) 2021 by the authors Licensee MDPI, Basel, Switzerland. This article is an open access article distributed under the terms and conditions of the Creative Commons Attribution (CC BY) license (https:// creativecommons.org/licenses/by/ $4.0 /)$.

\begin{abstract}
Broader understanding of waste management has the potential to bring about broad societal change impacting the climate crisis and public health. We present existing waste management tools and commercially-available games involving waste management, highlighting the strengths and opportunities left unaddressed by these tools in educational contexts and planning use cases. A survey motivates the need for enhanced interactive tools providing clear feedback through quickvisibility performance indicators. After identifying an opportunity to build upon highly-detailed multi-criteria simulation tools, we explore the need for easy-to-read performance metrics that will bring to the field of waste management easily identifiable and measurable key performance indicators (KPIs) that vary alongside factors affecting waste management policies. Such metrics are introduced and detailed as part of a unified waste management model. We then develop a representative gamified educational tool based upon this model to be used by students, decision makers planning real-world policies, and the public. This simulator is built upon the Unity Game Engine and emulates waste management techniques and resulting KPIs within the context of a virtual city.
\end{abstract}

Keywords: waste management; key performance indicators; gamified tools; simulation; modelling

\section{Introduction}

Waste management is an increasingly visible and essential element to functioning civilization. It is a particularly critical area of study in addressing growing climate [1] and public health [2] crises, yet in-depth exploration of this important topic is often not feasible to the average person as knowledge barriers and challenges relating to data access hinder public education efforts. In truth, it is these "average" individuals who most contribute to these problems and - through behavioral changes-might best support their amelioration.

Increasing public awareness of challenges and opportunities in waste management has the potential to bring about significant positive change. However, while the theory of waste management is studied widely, and observational data from real-world cities contribute to our modelling of it, waste management remains for many a difficult concept to understand-particularly as far as drivers of change are concerned. For many, a lack of "hands on" data makes developing intuition difficult. For others, poor understanding of critical evaluative performance metrics makes it tough to understand what effect policies might have on waste generation and management. 
Though tools have been developed to quantify waste management efficacy, and simulators have been built to allow individuals to "pull the levers" in a virtual environment to gauge their impact, these metrics and simulators are needlessly complex and therefore only serve a small audience. Existing simulations map inputs to performance indicators, requiring a complex setup to develop and adapt models for environments such as cities. This expertise requirement poses a barrier to knowledge that limits individuals' understanding of waste management systems, whereas broader knowledge of waste management could contribute positively towards the creation of enhanced social policies and constituent engagement in an effort to reduce and manage waste.

There is an opportunity to create an informative, easy-to-use simulator to help all types of individuals build an understanding of waste management and to evaluate the impact of various changes on waste management performance, particularly in the context of gamified tools. Building an understanding of challenges and opportunities within a larger network has the potential to drive positive change in waste generation and management. To that end, we build an educationally-focused tool in which students engage with a virtual city, changing operational parameters and observing these parameters' impact on waste management performance. Adding to the novelty of the designed simulation is an automated approach to selecting critical parameters and indicators to share with end users, helping to select the most-informative features as a means of educating users on what to look like when characterizing or designing their own waste management systems.

In this paper, we present existing waste management tools and commercially-available games involving waste management, and highlight the strengths and opportunities left unaddressed by these tools in educational and planning use cases. A brief survey motivates the need for enhanced interactive tools focused on providing feedback through quickvisibility performance indicators. After identifying an opportunity in building detailed tools with enhanced multi-criteria simulation capabilities, we explore the need for easy-toread performance metrics that will bring to the field of waste management easily identifiable and measurable key performance indicators (KPIs) that vary alongside factors affecting waste management policies. To address this need, we develop a representative gamified educational tool to be used by students and decision makers planning real-world policies. This custom-built simulator is built upon the Unity Game Engine and emulates waste management techniques and resulting KPIs within the context of a virtual city.

\section{Prior Art}

This section presents commercial games and research tools that include as a central theme elements of waste management and waste management modelling. We present popular games such as "Sim City 4" and "Cities: Skylines" alongside research tools like "NetLogo" and explore the level of depth of their waste management approach as well as their relative strengths and opportunities for improvement.

\subsection{Simulation Games and Gamified Tools}

Within cities, large populations and small regional boundaries lead to significant accumulation of solid waste, making waste management-whether through reduction, reuse, or recycling - essential. While waste is typically undesirable, elements of its management can be made "fun" through the exploration of waste management techniques in games such as those related to city building. One such example is the SimCity franchise of games, which was first released in 1989 and has since witnessed four significant updates. Each version includes increasingly-advanced waste management features. Haupt, Arnold, and Bidlingmaier found that SimCity 3000 (1999) and SimCity 4 (2003) included infrastructure systems that were comparable to real-world cities and realistic enough to support research $[3,4]$. SimCity 4's updated waste management system (elements of which are visible in Figure 1) is notable as the definitive version for research [4]. In this model, all waste created in the city fall are grouped together as "garbage", though there are three different ways to dispose of the city's waste: landfill, recycling, and energy conversion, with each having positive 
and negative associated attributes. Landfill is inexpensive when disposing of waste in small amounts, but it becomes expensive to maintain as the landfill reaches capacity-and residents find proximity to the dump undesirable. Recycling reduces the percentage of garbage relative to waste within the city, but may be cost-prohibitive. The waste-to-energy plant creates power for the city while eliminating significant waste, but it creates pollution and generates small amounts of power. SimCity 4 informs users of how well they manage the city's waste through different reporting means, including the city's desirability score and the user's Mayor Rating (https:/ / simcity.fandom.com/wiki/Mayor_rating, accessed on 24 October 2021), which both depend partially on how much garbage has piled up within the city. This rating varies from -100 to 100 and indicates citizens' approval of the mayor based on policies enacted, decisions made, and city statistics. The metric provides a quick "gut check" for players to determine sentiment related to their policies comprising social, economic, and other factors in one key performance indicator.

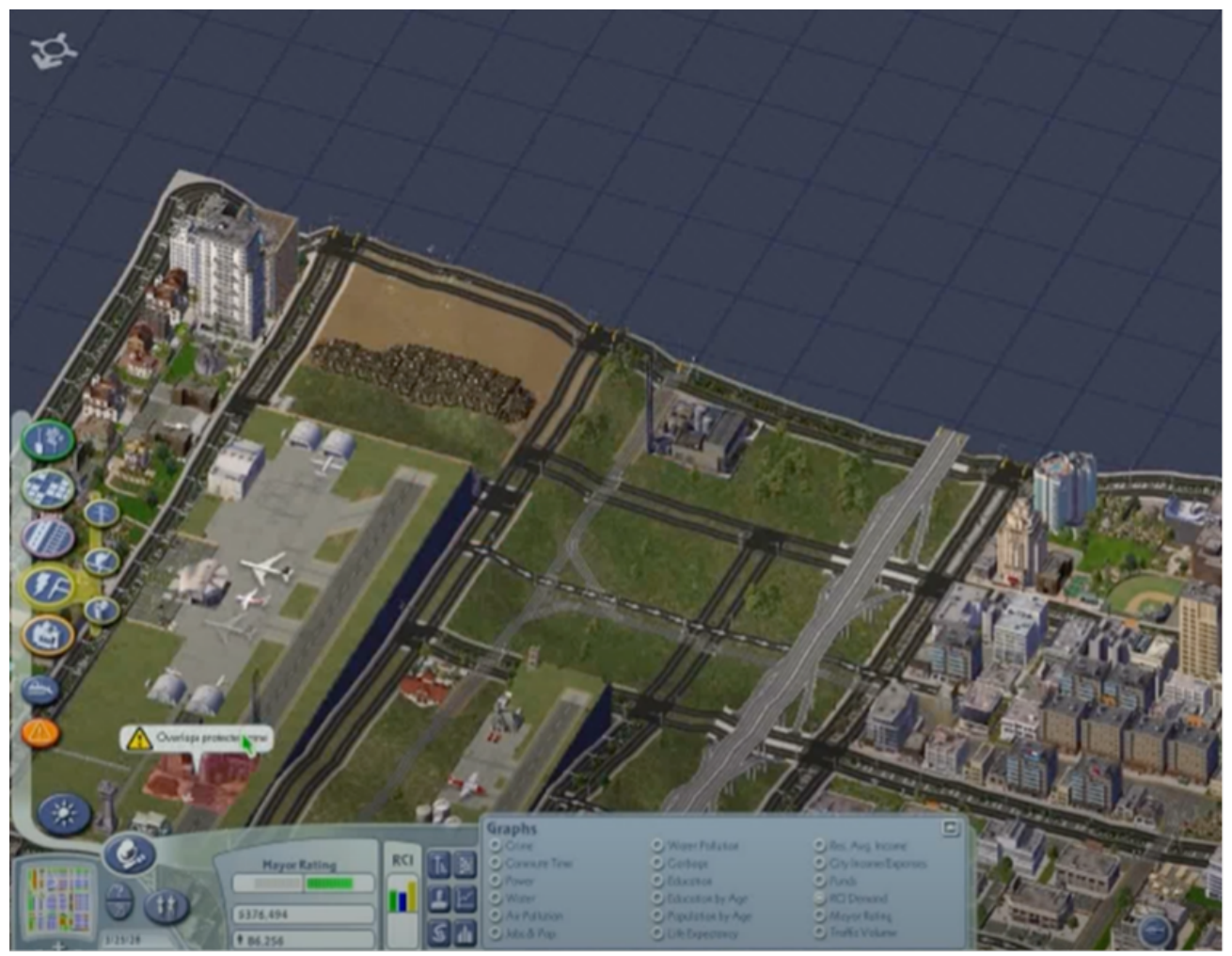

Figure 1. Landfill and waste-to-energy plant are potential options for waste management in SimCity 4.

Other city-building games have been used for urban development and waste management research -Fernández and Ceacero-Moreno [5] tested Cities: Skylines (2015) to see if it met the standards necessary to train environmentalists with gamified training scenarios as well as to see if it was able to correctly identify and manage natural hazards that occurred in the city. Cities: Skylines was also tested and scored in waste management, as well as energy production, and health systems, and it was deemed sufficiently realistic to be used in gamified learning [5]. Cities: Skylines is like SimCity 4 in that it groups all types of waste as garbage, and all garbage can be treated or disposed of through various means. In Cities: Skylines (Figure 2), waste disposal options include a floating garbage collector for contaminated water, an incineration plant, a landfill site, a recycling center, an ultimate recycling plant, a waste disposal unit, a waste processing complex, and a waste transfer facility. These methods all have trade-offs, such as the waste disposal unit creating a small amount of energy in exchange for a lot of pollution. One notable way in which Cities: Skylines varies from SimCity is that some methods, such as the waste processing complex and the recycling center, produce recycled materials from the waste, providing 
users with incentive to buy into more expensive recycling methods. Every building in the city also has a garbage buildup meter showing how much garbage the building has and its remaining capacity. If a building fills up with garbage, users are informed of the need to empty the building lest it be abandoned. Research into both the SimCity franchise and Cities: Skylines shows that commercial games are realistic enough to be viable for use in gamified research and education, which makes their systems valuable to urban planning and waste management.

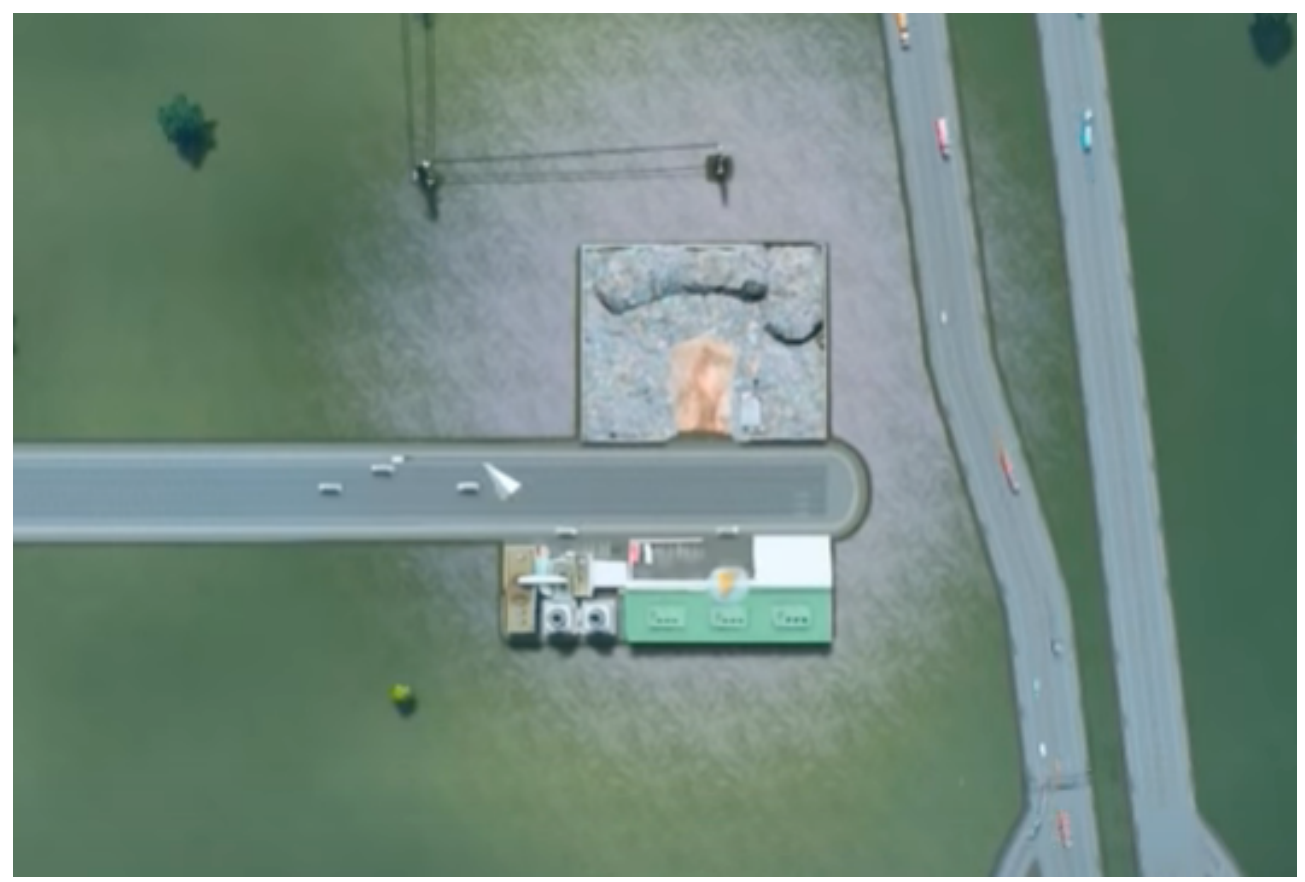

Figure 2. The Recycling Center, Incineration Plant, and Landfill Site are among the waste management options available to players of Cities: Skylines.

There have been recent research efforts to study the use of serious games in teaching and evaluating strategies for urban waste management. Wu and Huang created a waste management simulation game (Figure 3) that allows participants to control a city including its waste management, and see the ramifications of their decisions on the city [6]. Simulation users see waste accumulating in their city through a representative number of trashed 3D soda cans that litter the city's streets if waste is not adequately managed. The effects of this waste are also communicated to users through "official reports", which provide users with feedback and results related to their waste management choices, for example with one report informing users that the dogs in the city are getting sick as a result of consuming trash. $\mathrm{Wu}$ and Huang tested their waste management simulation on two subject groups, Taiwanese undergraduate students and Taiwanese elementary school students, and tracked both groups' decisions relating to balancing economic growth and the ecological effects of increased pollutants. Their research found that the undergraduate students generally put more importance on economic growth while ignoring the negative effects on the environment, while the group of elementary school students tried to balance economic growth with limiting environmental pollution, leading to issues with untenable resource allocation in other areas. Both situations focus on a core concept in teaching waste management, notably that there must be compromise. A city may hire more waste management workers and build more garbage trucks, but that will come at a monetary and environmental cost-not to mention the need to sequester or otherwise dispose of the waste. 


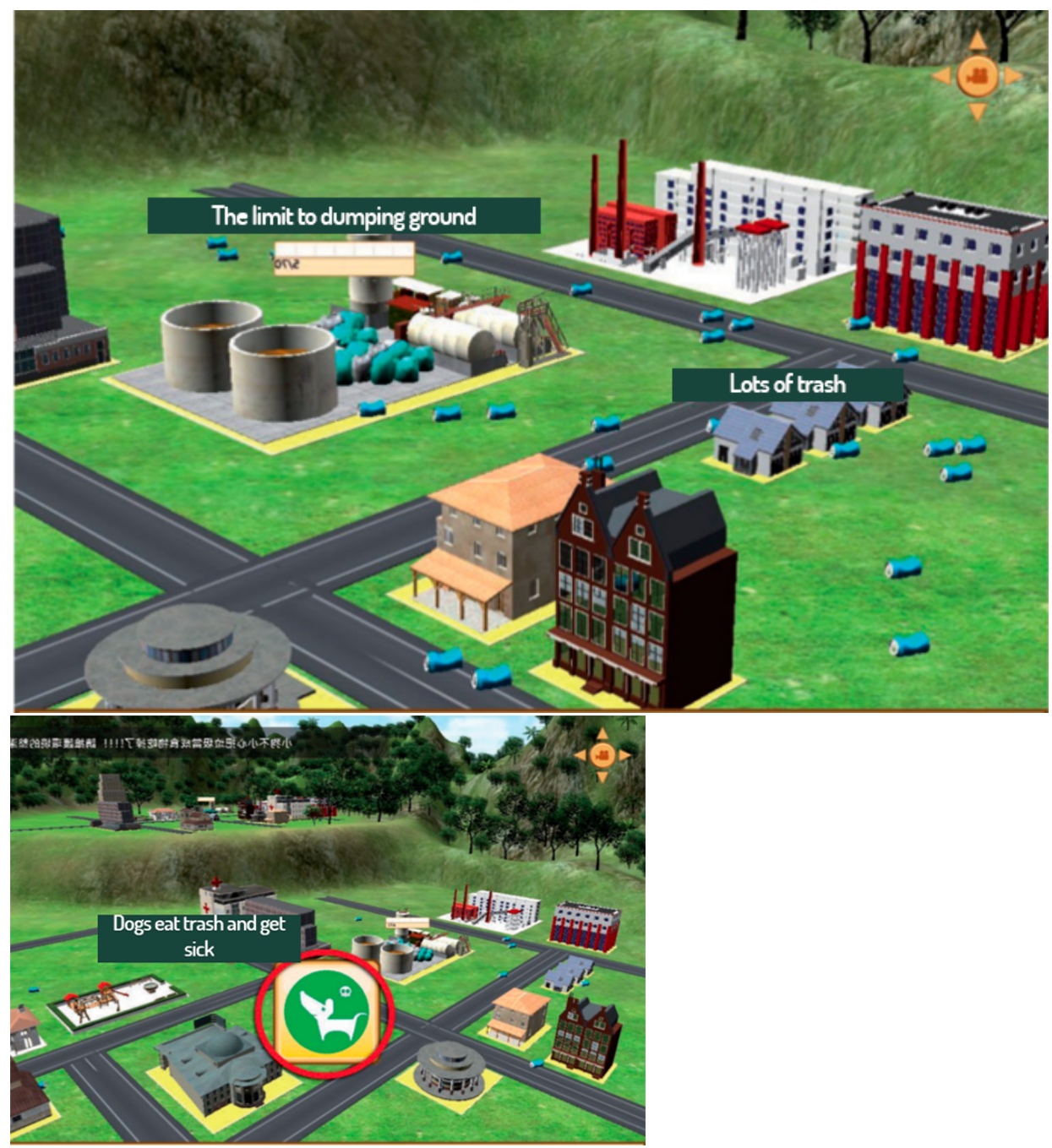

Figure 3. Wu and Huang's Waste Management Simulation Game evaluated two groups' planning decisions with respect to economic and environmental impact (Adapted with permission from Ref. [6]).

Wood of War is a serious game for waste management research created by Salazar et al. [7]. This game (Figure 4) uses mobile user data to identify areas with excessive solid waste build-up in Colima, Mexico throughout gameplay, and then compares these data to a map of areas in Colima, Mexico with significant amounts of rainfall to identify potential risk points where rain and trash could mix, blocking sewer drains and causing flooding. The game encourages players to go to these areas to destroy or dispose of enemies modeled to resemble sentient trash into piles of waste. Users are given extra points if they find a new area of excess waste and tag it using GPS for the developers [7]. This cycle of finding enemies in the real-world waste and finding trash-laden locations for more points-bearing enemies keeps game participation high and allows the developers to collect data valuable to local waste removal services [7]. Serious games like Wood of War can be specialized to a specific area of need like Colima, Mexico, where urbanization has been steadily growing in recent years while the waste management system is struggling to keep up with its urban population's excess waste. The game identifies areas of importance for waste management officials to address such that associated negative externalities, such as flooding from blocked sewer drains, can be managed responsively. Understanding where waste build-up occurs most frequently by using the game's data can also help officials build more efficient waste removal routes. 


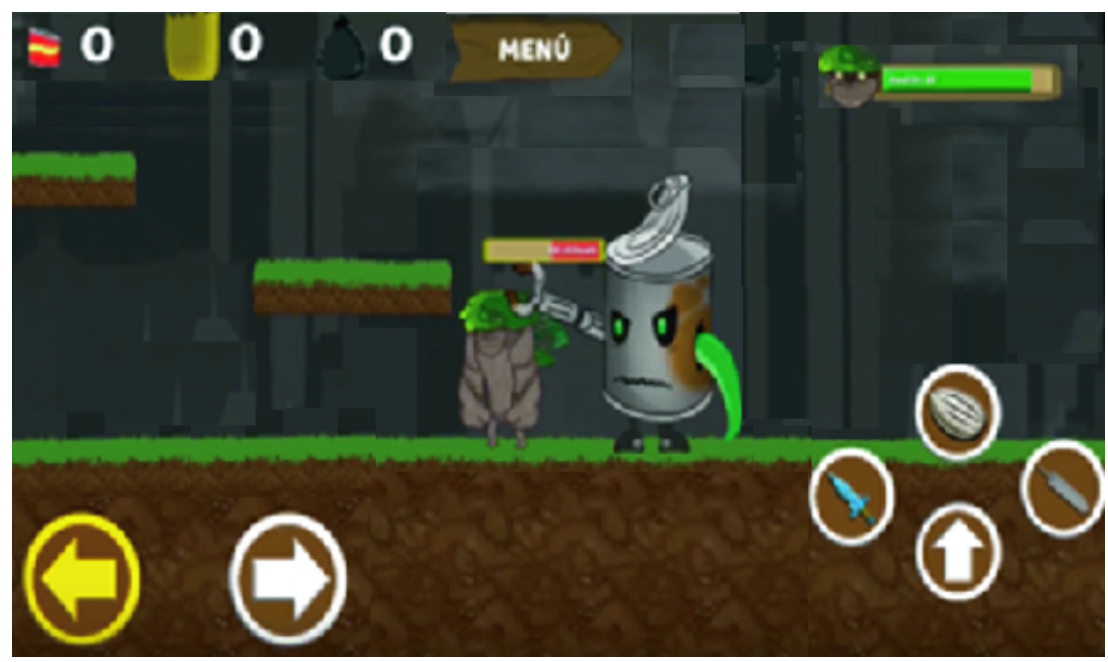

Figure 4. Wood of War encourages players to map trash by using real-world data to spawn trash monsters (Adapted with permission from Ref. [7]).

Other gamified software for waste management is the Multi-Agent-Based Modelling environment NetLogo [8] (Figure 5), developed in 1997 by Professor Uri Wilensky at the Center of Connected Learning (CCL) at Tufts University. This programmable software has been used in the modeling process in different areas including teaching, education, and research.

\section{NetLogo}

File Edit Tools Zoom Tabs Help

Interface Info Code

Edit Delete Add 0

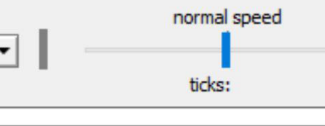

$\square$ view updates

continuous $\checkmark$ Settings

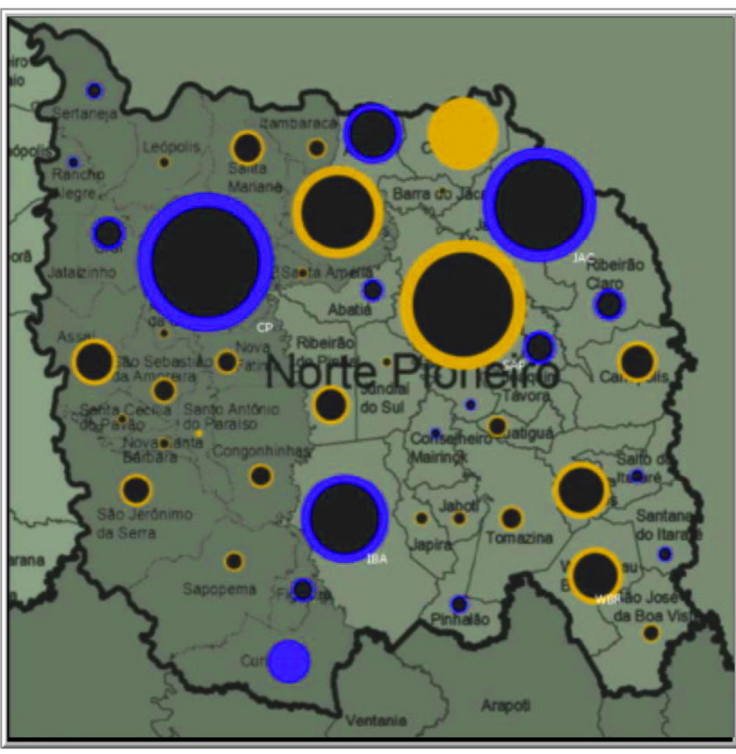

Figure 5. NetLogo was used to model and project waste management in the Norte Pioneiro region of Parana (Adapted with permission from Ref. [9]).

Eunice David Likotiko, Devotha Nyambo, and Joseph Mwangoka used NetLogo for the real-time simulation of waste management decisions. In the simulation, citizens are involved in optimizing the cost of waste collection services as well as providing decision algorithms to determine the best mobility for waste collections and bins. The authors' 
model verified the optimal waste collection route, aiding the development of smart and innovative waste management systems and modeling for real life scenarios. Continuous empirical data and Geographical Information Systems (GIS) are proposed to be used for further model extensions [10].

Addressing sociotechnical aspects of waste management, Vitor Miranda de Souza et al. [9] used the dynamics of waste generation, disposal and collection to assess the eco-effectiveness of a solid waste management plan using NetLogo. The authors assessed the eco-effectiveness of Parana's Norte Pioneiro region, forecasting waste generation, collection, and other waste management processes. Different population growth scenarios were simulated from 2020-2038, with different criteria analyzed to generate success metrics. This illustrates how NetLogo and similar ABMs may be used to inform socio-technical and socio-economic aspects of waste management plans as well as model the influence of policy [9].

In Table 1, we summarize these representative games or gamified tools and showcase their approach towards waste management.

Table 1. Comparison of waste grouping, disposal methods, notification methods, and use cases for Waste Management Systems in Gamified Tools and Commercial Games.

\begin{tabular}{|c|c|}
\hline $\begin{array}{l}\text { Commercial Games } \\
\text { /Research Tools }\end{array}$ & $\begin{array}{l}\text { Information About Waste } \\
\text { Management Systems }\end{array}$ \\
\hline \multirow{3}{*}{ SimCity 4} & All waste lumped as "garbage" \\
\hline & $\begin{array}{c}\text { Multiple disposal avenues } \\
\text { (Landfill, Recycling, Waste-to-Energy) }\end{array}$ \\
\hline & $\begin{array}{l}\text { Waste accumulation reported though } \\
\text { desirability reports, Mayor Rating }\end{array}$ \\
\hline \multirow{3}{*}{ Cities: Skylines } & All waste lumped as "garbage" \\
\hline & $\begin{array}{c}\text { Multiple disposal avenues } \\
\text { (Landfill, Recycling, Incinerator, Waste Processing, ...) }\end{array}$ \\
\hline & $\begin{array}{l}\text { Waste accumulation reported though } \\
\text { feedback bubbles }\end{array}$ \\
\hline \multirow{3}{*}{$\begin{array}{l}\text { Wu and Huang's } \\
\text { Research Tool [6] }\end{array}$} & All waste lumped as "garbage" \\
\hline & $\begin{array}{c}\text { Multiple disposal avenues } \\
\text { (Waste Product Dump, Incinerator, Environment Factory, } \\
\text { Trading Companies) }\end{array}$ \\
\hline & $\begin{array}{l}\text { Waste accumulation reported though } \\
\text { reports of garbage-driven natural disasters }\end{array}$ \\
\hline \multirow{3}{*}{ Wood of War } & Multiple waste monsters found with varied garbage piles \\
\hline & $\begin{array}{l}\text { Waste disposed of by defeating monsters } \\
\text { Real-world waste reported through GPS tags }\end{array}$ \\
\hline & $\begin{array}{l}\text { Real-world waste build-up is communicated to } \\
\text { developers, authorities }\end{array}$ \\
\hline \multirow{3}{*}{ NetLogo } & All waste types lumped \\
\hline & $\begin{array}{l}\text { Sociotechnical approach for complex waste management } \\
\text { and decision-making }\end{array}$ \\
\hline & $\begin{array}{l}\text { Waste management parameters (agents) executed serially. } \\
\text { Empirical calibration necessary to mirror real-world scenarios. }\end{array}$ \\
\hline
\end{tabular}

A clear opportunity remains to develop a tool that combines gamification and easeof-use with robust simulation and easy-to-read performance metrics to provide a quick feedback loop relating to policy and other changes. 


\section{Factors Affecting Waste-Key Performance Indicators}

Waste management tools are important to informing policy and educating the public about the consequences of waste and necessary remediation. Here, we evaluate critical waste parameters as a means of identifying the policy and procedural "levers" suitable for changing certain key metrics. We will use the developed metrics and models as the basis for the development of our novel waste management simulator.

\subsection{Approaching the Waste Management Problem}

Waste management modelling takes the form of a multi-criteria decision-making problem comprised of multiple variables. The general form of this kind of problems is expressed in Equation (1):

$$
\begin{gathered}
\min \boldsymbol{y}=F(\boldsymbol{x})=\left\{f_{1}(\boldsymbol{x}), \ldots, f_{n}(\boldsymbol{x})\right\} \\
\text { where } \boldsymbol{x}=\left(x_{1}, \ldots, x_{m}\right) \in \boldsymbol{X} \\
\boldsymbol{y}=\left(y_{1}, \ldots, y_{n}\right) \in \boldsymbol{Y}
\end{gathered}
$$

$F(x)$ represents multiple functions-relations (e.g., $f_{1}(x)$ ), $x$ represents measurable value variables and $y$ represents the possible multiple results. The variables $x_{i}$ can be discrete or continuous variables that belong to the bounded set $X$. In the real world, there are no infinite values of measurements, thus $f(x)$ factors need to be bounded. Similarly, $y_{j}$ represents the possible measurements of results.

To solve this type of problem, which is equal to finding their minimum (optimization), there are multiple methods - each one with pros and cons such as linear programming, ELECTRE methods, NSGA-II, and SPEA2. In our case, we formulate the optimization of the waste management problem:

$$
\min \boldsymbol{y}=F(\boldsymbol{x})=\sum_{i=1}^{n} w_{i} f_{i}(x)
$$

The weights $w_{i}$ represent the values that each factor $f_{i}(x)$ affects the waste management problem.

One possible waste management optimization could potentially approximate the "Green City" target. The cities, according to the "Green City" targets, tackle the most urgent environmental challenges involving five key areas: air, water, nature and biodiversity, circular economy and waste, and, lastly, noise. Mayors agreeing to the "Green City' targets must establish ambitious plans over-exceeding the requirements of the EU laws and implement policies to achieve those by 2030 [11]. However, this optimization is hard or impossible to solve as a unified solution since it may involve factors that are both measurable and non-measurable, such as human behavior or unanticipated environmental consequences. Some may be measured using field research techniques in real time (measurable variables), whereas others may require approximation. This may necessitate measuring the indirect effects of lesser-qualitative factors, such as policy changes, over time.

Based on the team's prior field research [12-16], we present what we believe to be the most crucial and measurable factors in waste management to inform the design and development of a waste management tool (as described in Section 4). This way, we are trying to model an approximation of the problem, but not optimize it, as our first step. These factors are the Key Performance Indicators and are showcased in Section 3.2.

\subsection{Key Performance Indicators}

Waste management systems are becoming more complex as regions shift from landfill to resource recovery-based solutions. This shift requires authorities to have information concerning different aspects of waste management in order to develop plausible models and actionable solutions [13]. The discovery of realistic and consistent data can be established through the use of Key Performance Indicators (KPIs) originating from real-world data 
collection. The purpose of these KPIs is to simplify assessing the perceived outcome of waste management within a virtual city in order to provide quantifiable evidence of performance [12].

The KPIs chosen to create a realistic user interface for the virtual city are amongst those widely used in waste management analysis [12,13,15-19] and include: Waste Compositional Analysis (MSW-C), Municipal Solid Waste Production (MSW-P), Municipal Solid Waste Recycling (MSW-R), Waste Production Rate (WPR), Waste Recovery Rate (WRR), Generation Rate (WGR), Waste Infrastructure (WI), Clean Index (CI), Accumulation Rate (AR) and Accumulation Index (AI), Mobility, Renewable Energy, Waste Water Treatment Plant, Air Pollution, and Strategies.

\subsubsection{Waste Compositional Analysis(MSW-C)}

MSW-C provides the data pertaining to the several produced waste streams, providing authorities with measurable data to design and implement waste prevention and waste management strategies $[13,18]$. MSW-C categorizes the types of material in solid waste such as PMD, Plastic Film, non-recyclable Plastic, Aluminium and Ferrous objects, Paper, Glass, Toilet and Kitchen Papers, Edible Food Waste, Inedible Food Waste, Organic Waste, and other materials [13]. To provide a representative baseline for the creation of a novel waste management simulator, a study in the Area of Paralimni, Cyprus was used. In the study, according to the population of the area in 2011 (18,601 residents), 15,100,000 tonnes of municipal solid waste were produced [12,13,15]. According to the compositional analysis carried out for the population of 18,601 , the numbers were scaled to reflect the population of the virtual city $(100,000)$. The estimated amount of each type of waste as scaled up for the virtual city is shown in Table 2.

Table 2. Waste Compositional Analysis categories, percent relative range and scaled amount of Waste for the virtual City.

\begin{tabular}{ccc}
\hline Categories of Waste & Range (\%) & Scaled Estimated Amount (tn) \\
\hline PMD & $5-30$ & 7639 \\
Plastic Film & $1-7$ & 3588 \\
Plastics Non-Recyclable & $1-3$ & 1835 \\
Aluminium/Ferrous & $0.5-2$ & 682 \\
Paper & $5-20$ & 8572 \\
Glass & $1-7$ & 4327 \\
Toilet and Kitchen Paper & $1-15$ & 9652 \\
Food Waste (edible) & $2-20$ & 12,055 \\
Food Waste (inedible) & $2-20$ & 4091 \\
Organic Waste(Green Waste, Yard Waste) & $2-20$ & 22,243 \\
Others & $1-10$ & 6494 \\
\hline
\end{tabular}

MSW-C is defined in Equation (3). The equation presents the ratio of the known reported amount of each category of $\mathrm{MSW}\left(\mathrm{Q}_{\text {knownMSW }}\right)$ to the total amount of $\mathrm{MSW}\left(\mathrm{Q}_{\text {TotalMSW }}\right)$ at a given time $(t)[18]$ :

$$
M S W-C=\frac{Q_{k n o w n M S W}(t)}{Q_{\text {TotalMSW }}(t)}
$$

The values are adapted from [13].

\subsubsection{Municipal Solid Waste Production(MSW-P)}

MSW-P represents the ratio of the amount of MSW produced $\left(\mathrm{Q}_{T o t}\right)$ to the population $(P O P)$ at a given time $(t)$ in the selected area (see Equation (4)). This indicator delivers a 
ratio of the average waste quantity per capita $[12,15,18]$. City geometry and population determine the range of this number:

$$
M S W-P=\frac{Q_{T o t}(t)}{Q_{P O P}(t)}
$$

\subsubsection{Municipal Solid Waste Recycling (MSW-R)}

MSW-R measures the MSW that has been recycled (QRecycledMSW) in comparison with the total solid waste produced (QTotalMSW) at a moment in time $(t)$, per Equation (5). Table 3 presents the categories of the recycled waste which are PMDs, Paper and Glass $[12,13,16]$. These numbers will be useful in the strategic planning of Waste Management Systems, give information on the prevention activities performed in each area as well as provide data regarding the technical aspects of Waste Management like Waste Bin Capacity, types of Recycle Bins in each area, etc. [12]:

$$
M S W-R=\frac{Q_{\text {RecycledMSW }}(t)}{Q_{\text {TotalmSW }}(t)}
$$

The data used in Table 3 were obtained from www.greendot.com.cy, accessed on 24 October 2021, and reflect figures for Paralimni, Cyprus in 2011 as scaled to fit the virtual city's population of 100,000 [20]. Green Dot Cyprus Public Co Ltd. is a nonprofit organization and the first collective recycling system approved by the Ministry of Agriculture, Rural Development and Environment in Cyprus. It is established based on the Packaging and Waste Packaging (Amendment) Law, 2005 (Law No. 159(I)/2005) of Cyprus and implemented based on Directive 2003/35/EC of the European Parliament and the Council of the European Union [21,22].

Table 3. Municipal Solid Waste Recycling Categories and Range.

\begin{tabular}{ccc}
\hline Categories & Range (\%) & Estimated Amount (tn) \\
\hline PMD & $50-100$ & 3819 \\
Paper & $50-100$ & 4286 \\
Glass & $80-100$ & 3461 \\
\hline & Total & 5172 \\
\hline
\end{tabular}

\subsubsection{Waste Production Rate (WPR)}

WPR illustrates fluctuations in the volume of waste produced annually. These fluctuations inform the actions necessary to minimize waste production increases [12,18]. With the use of WPR, a possible percentage of achievement until a given time can be evaluated. WPR can be calculated using Equation (6):

$$
W P R=\frac{Q_{\text {total waste production next year }}(t)}{Q_{\text {total waste production previous year }}(t)}
$$

\subsubsection{Waste Recovery Rate (WRR)}

WRR indicates the recovery of generated waste in a specific period (Equation (7)). Numerous recovery options are available, including recycling, reuse, waste to energy, etc. WRR should not be misinterpreted for MSW-R, as waste stream recycling states the actual percentage of recycled material in a particular area with a specific population density, whereas WRR refers to the potential of recovering $100 \%$ of any significant waste stream like plastic, paper, etc. Waste recovery informs waste prevention strategies to reach the full potential of recovery of a stream $[12,16,23]$. The recovery rate of each material is listed in Table 4: 


$$
W R R=\frac{\text { RecoveredWaste }}{M S W-P}
$$

Table 4. Typical municipal solid waste recovery rates.

\begin{tabular}{lccc}
\hline \multirow{2}{*}{ Categories } & \multicolumn{2}{c}{ Range of Recovery (\%) } & \multirow{2}{*}{ Estimated Waste Recovered (tn) } \\
\cline { 2 - 3 } & Min & Max & \\
\hline PMD & 50 & 100 & 3819 \\
Aluminium/Ferrous & 50 & 100 & 341 \\
Paper & 50 & 100 & 4286 \\
Glass & 80 & 100 & 3461 \\
Food waste & 50 & 100 & 8073 \\
Green Waste & 80 & 100 & 17,794 \\
\hline & & & 37,776 \\
\hline
\end{tabular}

\subsubsection{Waste Generation Rate (WGR)}

WGR estimates the generation of waste in the selected area in unit of time (i.e., per day, week, month, or year) and is represented by Equation (8) [16,24]. As product and service demands increase along with economic and population growth, waste generation is inevitable. World waste production was estimated at approximately 1.30 billion tonnes in 2012 and by 2016 waste generation reached 2.01 billion tonnes of waste. If waste generation continues in the same trajectory, by 2050, this number is estimated to reach on average 3.40 billion tonnes of waste $[25,26]$. The indicator provides an assessment of an area's ecological trends as well as showcase the effectiveness of any sustainability practises and strategies implemented in that area according to the increase or decrease of its value.

WGR will vary with the population density of each selected area in the virtual city. As the total quantity of waste produced for the 100,000 citizens is 65,000 tones, an average citizen will produce $650 \mathrm{~kg}$ /year.

$$
W G R=(\text { Waste production in one area }(\mathrm{kg})) \times(\text { Citizens in the same area in one day })
$$

\subsubsection{Waste Infrastructure (WI)}

A crucial indicator (Equation (9)) concerning environmental performance is the available waste management infrastructure. WI estimates without limitation the number of bins and collection bins in general in a specific area. It provides useful information about the current infrastructure in relation to the residential density of that area $[12,13,16]$.

Depending on area, the user will be able to choose from one to all the bins listed in Table 5. WI depends strongly on the population density; as population density increases, the number of bins will increase proportionally. Depending on the user's choice, the outcome will be different. For population density of 100,000 citizens and 65,000 tones of waste, 750 bins are required. This indicator provides useful information to inform policies and actions required in relation to the existing infrastructure and number of citizens $[12,13]$.

$$
W . I=\frac{\# \text { of bins }}{\text { Population density }}
$$

The range of recycle bins per population density must comply with the requirements of the level of services presented in Section 3.2.8. The minimum range of waste bin capacity must be the minimum $0.5-1.5 \mathrm{~L} /$ capita in line with $3(\mathrm{C})$ and maximum/over 1.5-2.5 L/capita as mentioned in level 1(A) in Table $6[12,15]$. 
Table 5. Types of recycling bins proposed range per population density and range.

\begin{tabular}{ccc}
\hline Categories & Bin Colour & Proposed Range \\
\hline Recycle Bin for: & & \\
\hline Plastics & Yellow & \\
Paper & Brown & min: W.I $\geqslant 0.5-1.5$ L/capita \\
PMD & Blue & max: W.I $\geqslant 1.5-25$ L/capita \\
Mixed waste & Green & \\
Food Waste & Pink & \\
Green Waste & Light Green & \\
Batteries & Transparent & \\
Glass Packaging & Grey & \\
Aluminium & Perforated & \\
\hline
\end{tabular}

\subsubsection{Clean Index (CI)}

$\mathrm{CI}$ rates how clean the selected area is using Equation (10), where $N I_{c o l}$ is the number of items collected (i.e., cigarette butts, PMD, papers, other plastics, etc.) and Sur is the surface in $\mathrm{m}^{2}$ of the specific selected area. $K$ is a constant equalling $20[12,15,16,27]$.

Table 6 is used to scale the area accordingly [16]. Using CI, the infrastructure of the selected area can be assessed to optimize activities including waste collection period, cleaning department size, number of recycling bins per citizen, etc. The indicator was first suggested by Alkalay [27]:

$$
C . I=\frac{N I_{\text {col }}}{S u r} K
$$

According to $[12,15,16]$, the Level of Services (LoS) may be interpreted as:

- 1(A): Outstanding waste collection, defined as at least three times daily (morning, midday, afternoon). Waste bins exist at least every 100-200 $\mathrm{m}$ as well as other waste infrastructure (such as separated recycling bins, collection of hazardous waste, or increased waste awareness and informational signs). Mechanical cleaning of roads two times weekly, with waste bin capacity at least in the range of 1.5-2.5 L/guest.

- 2(B): Acceptable collection of waste, three to four times/week and twice/day for some areas (e.g., morning and afternoon collection, average waste bin separation of $200-400 \mathrm{~m}$ with other waste infrastructure (e.g., recycling bins). Waste bins capacity is at least 1.0-1.4 L/visitor. Informational signs are visible, and mechanical road cleaning occurs at least weekly.

- 3(C): Average collection of waste twice weekly and once per day in some areas. On average, waste bins are spaced ever $500 \mathrm{~m}$ with some other waste infrastructure available. Waste bin capacity varies from $0.5-1.4 \mathrm{~L} /$ visitor with limited awareness and informational signs, with only periodic road cleaning.

- 4(D): Periodic collection of waste-approximately once weekly, with limited public waste bins or other infrastructure, zero implementation of mechanical cleaning of the roads and waste bin capacity $0.5-1.4 \mathrm{~L} /$ visitor.

- 5(E): Zero formal cleaning programs in the area, no waste infrastructure and no mechanical cleaning of the roads. Little to no waste awareness or signage.

Table 6. Clean Index Identification.

\begin{tabular}{cccc}
\hline Quality & Level of Sevices (LOS) & CI & Identification \\
\hline Very Clean & $1(\mathrm{~A})$ & $0-2$ & No litter seen \\
Clean & $2(\mathrm{~B})$ & $2-5$ & No litter seen over a large area \\
Moderate & $3(\mathrm{C})$ & $5-10$ & A few pieces of litter visible \\
Dirty & $4(\mathrm{D})$ & $10-20$ & A lot of litter visible \\
Very Dirty & $5(\mathrm{E})$ & $20+$ & Most of the area is covered in litter \\
\hline
\end{tabular}




\subsubsection{Accumulation Rate (AR)}

AR evaluates the accumulation of waste per unit of surface area and unit time (items $/ \mathrm{m}^{2} /$ day) (Equation (11)) $[12,13,17]$. AR is directly affected by population density as, consequently, the more people there are in an area, the more waste will exist [28]. $T$ represents the time elapsed between the survey and the last cleaning activity which also gives an indication of the number of days since the responsible authority completed a full cleaning of the researched area [29]:

$$
A \cdot R=N I_{c o l} / S / T
$$

\subsubsection{Accumulation Index (AI)}

AI takes into account the rate of accumulation of liter (Equation (12)), complementing $\mathrm{CI}$ and AR. While CI assesses area cleanness and hence the collection period, AI and AR evaluate the accumulation of waste at a given area in a specific period [15]. Table 7 represents the classification given by [16]:

$$
A . I=\log 10(A . R \times 1000000)
$$

LOS is explained in Table 6.

Table 7. Accumulation rate and index classification.

\begin{tabular}{ccccc}
\hline & LOS & WAI & WAR (items $/ \mathbf{m}^{2} /$ day) & WAR (items $/ \mathbf{k m}^{2} /$ day) \\
\hline Extremely Low & 1 & $\leq 1$ & 0.000001 & 1 \\
Very Low & 2 & $1-2$ & 0.00001 & 10 \\
Low & $2-3$ & $2-3$ & 0.0001 & 100 \\
Moderate & 3 & $3-4$ & 0.001 & 1000 \\
High & 4 & $4-5$ & 0.01 & 10,000 \\
Very High & $4-5$ & $5-6$ & 0.1 & 100,000 \\
Extremely High & 5 & $\geq 6$ & 1 & $1,000,000$ \\
\hline
\end{tabular}

\subsubsection{Air Pollution}

Air Quality Indication (AQI) illustrates the gas emissions in the virtual city including simulated $\mathrm{CO}_{2}, \mathrm{CO}, \mathrm{NO}, \mathrm{NO}_{2}, \mathrm{SO}_{2}, \mathrm{O}_{3}$ and Benzene as shown in Table 8. The correlation of air pollution with human activity is of significant interest, and are driven by emission sources like vehicles and industrial processes [30]. Greenhouse gas emissions from solid waste treatment emerge mainly from uncontrolled disposal and dumping as well as incineration [26].

The urbanization of the last 60 years has created high transportation network density, encouraged building development, and driven population growth that promote the consumption of variously-sourced energy sources and energy in general while the lifestyle in urban environments make the application of environmentally conscious actions appear to be a far off necessity rather than a personal responsibility [31]. Air quality management is vital to both protect human health and improve the quality of life in urban and industrial areas [32]. Strategies to better handle waste management can decrease greenhouse gas emissions by as much as 200 million tonnes by 2030 [26,33].

The limits were provided considering the existing proposed limits by www.airquality .dli.mlsi.gov.cy/, (accessed on 24 October 2021) presenting the pollutants concentration values in Cyprus in real time. The results can be easily accessed from the official Air Quality Cyprus mobile application [34]. 
Table 8. Gas emissions observed.

\begin{tabular}{|c|c|c|c|c|c|}
\hline Categories & Range (\%) & Low & Moderate & High & Very High \\
\hline$P M_{10}$ & $0-100$ & $0-50$ & 50-100 & $100-200$ & $>200$ \\
\hline$P M_{2.5}$ & $0-100$ & $0-25$ & $25-50$ & 50-100 & $>100$ \\
\hline Carbon Dioxide $\left(\mathrm{CO}_{2}\right)$ & \multicolumn{5}{|c|}{ To be defined } \\
\hline Carbon Monoxide (CO) & $0-100$ & $0-7000$ & $7000-15,000$ & $15,000-20,000$ & $>20,000$ \\
\hline Nitrogen Monoxide (NO) & $0-100$ & & & & \\
\hline Nitrogen Dioxide $\left(\mathrm{NO}_{2}\right)$ & $0-100$ & 0-100 & $100-150$ & $150-200$ & $>200$ \\
\hline Sulphur Dioxide $\left(\mathrm{SO}_{2}\right)$ & $0-100$ & $0-150$ & $150-250$ & $250-350$ & $>350$ \\
\hline Ozone $\left(\mathrm{O}_{3}\right)$ & $0-100$ & $0-100$ & $100-140$ & $140-180$ & $>180$ \\
\hline Benzene $\left(\mathrm{C}_{6} \mathrm{H}_{6}\right)$ & $0-100$ & $0-5$ & $5-10$ & $10-15$ & $>15$ \\
\hline
\end{tabular}

\subsubsection{Mobility}

The Mobility metric indicates the public transportation available for a given population density. Mobility is directly interlinked with fuel consumption and greenhouse gas emissions. This indicator helps authorities explore new innovative mobility plan strategies in order to limit the environmental impact of transportation, especially in urban areas [35]. The use of public transportation in the simulation versus the choice of the user to transfer by car will make a crucial difference regarding gas emissions. The choices of public transportation offered in the virtual city are listed in Table 9.

Table 9. Available transportation choices.

\begin{tabular}{c}
\hline Transportation \\
\hline Buses \\
Trams/Trolleys \\
Trains/Underground Metro \\
Bike lanes \\
Walk lanes \\
Electric Cars \\
\hline
\end{tabular}

Important criteria for the selection of Mobility transportation Choices should be when applicable:

- [A] Public Transportation must line with existing EU regulations regarding Transportation means (i.e., $80 \%$ Electric Cars by 2050 [36])

- $\quad[B]$ They must cover existing National plans and targets.

- [C] Satisfy the needs of Public Transportation for the maximum population density requirements.

- [D] Contribute to the existing National Plans to reduce Carbon Dioxide emissions.

\subsubsection{Green Space}

The Green Space KPI denotes free green space per population density in $\mathrm{m}^{2}$ or $\mathrm{km}^{2}$ (Equation (13)). Green spaces include parks, open-air sport facilities, playgrounds, etc. [37].

Strategic urban planning for land management encourages good living conditions due to psychological factors and also the reduction of the environmental impact of urban areas [38]. Natural and semi-natural areas designed in urban cities serve not only recreational and aesthetic stress reducing purposes but provide an improved living environment. This is achieved by natural processes in the presence of biodiverse green spaces like purifying the air and water, providing protection from extreme weather conditions like heat and thunderstorms, and also contributing to the reduction of noise pollution [39]. 
The strategic distribution of green areas across the virtual city is essential in order for all the citizens to have access to these green spaces. Therefore, Green Space must be closely coupled to population density as well available public free space.

Table 10 indicates the choices of the user regarding green space categories. The limits were chosen according to the recommendations of the World Health Organization [40,41].

$$
\text { GreenSpace }=\frac{\text { Freegreen space }}{\text { Population density }}
$$

Table 10. Green space requirements per capita.

\begin{tabular}{cc}
\hline Green Space Categories & Green Space Requirements $\left(\mathrm{m}^{3} /\right.$ capita) \\
\hline $\begin{array}{c}\text { Green Space (Parks, Playgrounds, } \\
\text { Open-air Sport Facilities) }\end{array}$ & $\min : 9 \mathrm{~m}^{3} /$ capita \\
\hline
\end{tabular}

\subsubsection{Renewable Energy Sources (RES)}

Fossil fuels have been a primary energy source for cities for decades. Wasteful handling of raw materials, food, and energy made necessary the creation of innovative renewable energy technologies [42]. The use of renewable energy sources, coupled with emerging energy storage technologies, may present a more balanced approach towards sustainable socioeconomic development and prosperity [43]. Production of renewable domestic energy is of interest as a means of managing the need for raw materials that each technology requires $[43,44]$.

The RES available are listed in Table 11, calculated per population density or $\mathrm{km}^{2}$. The available categories of RES and the percentage they hold in the Total Energy production are Photovoltaic (P/V) Parks (1-5\%), P/V Houses (5-100\%), and Wind Parks (1-4\%) according to the Transmission System Operator Cyprus for the year 2020 and the Cyprus Energy Regulatory Authority $[45,46]$. The indicator measures the number of RES in place and national targets.

Table 11. Renewable Energy Sources percentage share in Total Energy Production.

\begin{tabular}{cc}
\hline Category & RES Share in Total Energy Production (MWh) \\
\hline RES (P/V Parks, & $\min : 11.7 \%(63,176 \mathrm{MWh})$ \\
P/V houses, Wind Parks) & $\max \geq 32 \%(\geq 114,760 \mathrm{MWh})$ \\
\hline
\end{tabular}

Data provided by the Transmission System Operator Cyprus for the year 2020 and the Cyprus Energy Regulatory Authority $[45,46]$. The data collected concerned the population of Cyprus of 888,000 citizens for 2019 and were scaled down for the 100,000 of the virtual city [47]. The optimum maximum limit of 32\% of Renewable Energy Sources in Total Energy Production is derived from the Policy framework of the European Commission in 2014 for 2030 [48].

\subsubsection{Waste Water Treatment (WWT)}

Urban wastewater management constitutes a challenging topic due to poor synchronization among infrastructure development and population growth. The main concern of Waste Water Treatment is to protect the environment and specifically the surface of waters from organic pollution and the degradation of aquatic life as well as the protection of human health [49]. In real life situations, agglomerations and collection systems provide a much more provable approach regarding the level of treatment of wastewater. Agglomerations, referred to as a sufficiently concentrated area for wastewater to be collected and further conducted to a nearby treatment plant, are usually required to be sufficient for a number of populations equivalent (1 Population Equivalent (P.E) unit is the organic biodegradable load of having a five-day biochemical oxygen demand (BOD5) of $60 \mathrm{~g}$ of oxygen per 
day) [50]. The Urban Waste Water Treatment Directive (WWTD) which is directly linked to zero waste ambitions in the European Green Deal requires all European settlements to provide their cities with agglomerations of the size of 2000 population equivalents or above and equipment (i.e., Collection systems, Wastewater Treatment Plants) sufficient for the waste water [51].

In this section, the indicator of Equation (14) presents only the number of houses connected to the waste water treatment plant with a range of values from $0-100 \%$ [52]. This range submerges from data of Eurostat\% [53], where, until 2018, Denmark, Latvia, France, Malta, Finland, Austria, and the Netherlands had a 100\% of their population connected to a Wastewater Treatment facility, whereas Kosovo maintained only a $0.52 \%$ of the population connected to wastewater treatment with the very next being Serbia with 14.12. Due to the fact that the quality of wastewater treatment emerges from the level of treatment (Primary, Secondary, Tertiary) as well as the available infrastructure mentioned above (Agglomerations and collection system), the indicator will be used regarding the following conditions:

- [A] The wastewater treatment plant will perform all primary, secondary, and tertiary treatment [50].

- [B] Agglomerations and collection systems are $100 \%$ treated in the wastewater treatment plant.

- [C] The P.E of each area will always be within the limits provided by WWTD $(\geq 2000$ P.E).

- [D] Wastewater Treatment plants will protect environment and surface waters as well as human health [49]:

$$
\text { W.W.T }=\frac{\text { connected population }}{\text { total population }} \times 100 .
$$

\subsubsection{Strategies}

Seeking to grow a sustainable world has necessarily increased the strategic relevance of waste prevention [54]. To reduce the impact of industrial processes that affect severely the environment, corporate policies must be set in place. The main focus of waste prevention strategies is the reduction of landfill material, resource saving, the protection of human health, and improved quality of life by sustainable economic development $[14,18]$. Strategies available include circular economy, the European Green Deal, the United Nations Sustainability Goals, Zero Waste Policy, Energy Recovery, Smart Cities, Environmental Management Systems, and R-strategies [12,28,43,55-57]. Strategies like these, effectively implemented, will create a social shift in attitude that is vital to the success of any policy or indicator. Table 12 illustrates the user's available choices [16,43].

Table 12. Strategies for action.

Categories
Circular Economy
European Green Deal (EGD)
Znited Nations Sustainability Goals (UNSDGs)
Zero Waste Policy
Low Carbon Society
Waste Prevention
Energy Recovery
Smart City
Environmental Management Systems (i.e., ISO14001, EMAS)
R-strategies

Corporate policies, such as ISO 14001, EMAS, zero waste, etc., can reduce the impact of industrial processes on the environment by limiting energy requirements, im- 
proving waste water treatment processes, and increasing the social acceptance of such initiatives [12,16,28,43,55-57].

At the same time, alternative energy scenarios which revolve around renewable energy resources and/or energy recovery ensure the supply of reliable and efficient energy and utilisation [58]. The emissions related to fossil fuels combined with climate change have already forced many countries worldwide to explore strategies for better energy sources compared to the global energy mix [59]. The transition to clean renewable energy and zero emissions can be enabled by a shift to a more circular economy [43].

The concept of a Circular Economy (CE) is powerful tool many social groups including policy makers, urban designers, and academics employ to fundamentally link resource use with waste. CE is recognized by the European Union as an "irreversible global mega trend" and is now an essential strategy for the accomplishment of the goals set in the European Green Deal $[43,60]$. The shift from a linear to circular approach can result in the implementation of environmental and economic policies in order to achieve waste prevention, reuse, and recycling which directly contributes to clean production and manufacturing. This creates a stronger economy where resources are used in a more sustainable way $[12,24]$.

An important category included in strategic sustainable development are the prevention activities carried out by individuals or groups of people in a social structure. The awareness activities related to waste prevention practices like reuse, recycling, refurbishment, and material recovery are important for the successful transition to a sustainable, environmentally acceptable development. Both domestic and industrial changes can lead to the reduction of greenhouse gas emissions and to the development of new waste treatment concepts $[12,61]$.

The secret to waste prevention plans and to the implementation of strategies like these is social behaviour and acceptance [14]. A broad-based willingness to contribute to sustainable development is the fastest way to meet the standards and targets set by the policy makers and urban developers [18]. While the behavior regarding household waste prevention activities has been explored mostly on a qualitative rather than quantitative level, activities focusing on the reduction of waste and thoughtful use of everyday products are likely to reduce landfill waste [14,62]. It is vital for citizens to understand that waste prevention is everybody's responsibility and taking thoughtful actions before an item becomes waste is an essential step to meet the sustainability standards [12].

Actions like these are presented in Table 13 where the available categories to assess any prevention activities are introduced, e.g., food waste reduction or participation in home composting, participation in web-platforms related with waste management in household level, etc. [13].

Table 13. Prevention activities.

Categories
Use of leftovers
Use of reusable Grocery Bags
Reusable Coffee Cup
Home Composting
Food Waste Campaign
Donations where possible (i.e., Toys,Books,clothes etc)
Book exchanges
Smart shopping list (buying exact necessities from stores)
Keeping vegetables and fruits in loosely tied bags
Reuse of electrical appliances
Electrical Appliances repair stores to extend life time of devices

\subsubsection{Correlations among KPIs}

When researching the Environmental Performance of an area, correlating the Key Performance Indicators reveals scenario-dependent interaction. Table 14 offers a brief 
qualitative approach to codify these correlations that, with methodological analysis, may lead to not only qualitative but also quantitative assessment of an area's sustainability by addressing connections and dependencies between the indicators for the creation of links on waste management systems [63].

Table 14. Proposed Correlations between KPIs which will be defined through research at field and software such as lifecycle assessment, or other simulation tools.

\begin{tabular}{|c|c|c|c|c|c|c|c|c|c|c|c|c|c|c|c|}
\hline & MSW-C & MSW-P & MSW-R & WPR & WRR & WGR & WI & $\mathrm{CI}$ & $\mathbf{A R}$ & AI Air Pollution & Mobility & Green Space & $\begin{array}{c}\text { Renewable } \\
\text { Energy }\end{array}$ & \begin{tabular}{|c|} 
Waste Water \\
Treatment Plant
\end{tabular} & Strategies \\
\hline MSW-C & & $\checkmark$ & $\checkmark$ & $\checkmark$ & $\checkmark$ & $\checkmark$ & & & & & & & & & $\checkmark$ \\
\hline MSW-P & $\checkmark$ & & $\checkmark$ & $\checkmark$ & $\checkmark$ & $\checkmark$ & & & & & & & & & $\checkmark$ \\
\hline MSW-R & $\checkmark$ & $\checkmark$ & & $\sqrt{ }$ & $\sqrt{ }$ & $\sqrt{ }$ & $\checkmark$ & & & & & & & & $\checkmark$ \\
\hline WPR & $\checkmark$ & $\checkmark$ & $\checkmark$ & & $\checkmark$ & $\checkmark$ & $\checkmark$ & & & & & & & $\checkmark$ & $\checkmark$ \\
\hline WRR & & & $\checkmark$ & & & $\checkmark$ & $\checkmark$ & & & & & & & & $\checkmark$ \\
\hline WGR & $\checkmark$ & $\checkmark$ & $\checkmark$ & $\checkmark$ & $\checkmark$ & 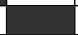 & $\checkmark$ & & $\checkmark \mid$ & $\checkmark$ & & & & & $\checkmark$ \\
\hline WI & $\checkmark$ & & $\checkmark$ & & $\checkmark$ & & & & & & & $\checkmark$ & & & $\checkmark$ \\
\hline $\mathrm{CI}$ & $\checkmark$ & & & & & $\sqrt{ }$ & $\checkmark$ & & $\checkmark \mid$ & $\checkmark$ & & $\checkmark$ & & & $\checkmark$ \\
\hline AR & $\checkmark$ & & & & & $\checkmark$ & $\checkmark$ & $\checkmark$ & & $\checkmark$ & & & & & $\checkmark$ \\
\hline AI & $\checkmark$ & & & & & $\sqrt{ }$ & $\checkmark$ & $\checkmark$ & $\checkmark$ & & & & & & $\sqrt{ }$ \\
\hline Air Pollution & $\sqrt{ }$ & & & & & & $\checkmark$ & & $\checkmark \mid$ & $\checkmark$ & $\sqrt{ }$ & $\sqrt{ }$ & & $\sqrt{ }$ & $\sqrt{ }$ \\
\hline Mobility & & & & & & & & & & $\checkmark$ & & $\checkmark$ & & & $\sqrt{ }$ \\
\hline Green Space & & & & & & & $\checkmark$ & $\checkmark$ & \begin{tabular}{|l|l}
$\checkmark$ & \\
\end{tabular} & $\checkmark$ & $\checkmark$ & & & & $\checkmark$ \\
\hline Renewable Energy & $\checkmark$ & & & & & $\checkmark$ & & & & $\checkmark$ & $\checkmark$ & & & $\checkmark$ & $\checkmark$ \\
\hline Waste Water Treatment Plant & & & & & & & & & & & & & & & $\checkmark$ \\
\hline Strategies & $\checkmark$ & $\checkmark$ & $\checkmark$ & $\checkmark$ & $\checkmark$ & $\checkmark$ & $\checkmark$ & $\checkmark$ & \begin{tabular}{|l|l}
$\checkmark$ & \\
\end{tabular} & $\checkmark$ & $\checkmark$ & $\checkmark$ & $\checkmark$ & $\checkmark$ & \\
\hline \multicolumn{16}{|c|}{ Acronyms and Terms } \\
\hline MSW-C & \multicolumn{15}{|c|}{ Waste Compositional Analvsis } \\
\hline MSW-P & \multirow{2}{*}{\multicolumn{15}{|c|}{ Municipal Solid Waste Production }} \\
\hline MSW-R & & & & & & & & & & Inicipal Solid Wast & te Recyclir & & & & \\
\hline WPR & \multicolumn{15}{|c|}{ Waste Production Rate } \\
\hline WRR & \multicolumn{15}{|c|}{ Waste Recovery Rate } \\
\hline WGR & \multicolumn{15}{|c|}{ Waste Generation Rate } \\
\hline WI & \multirow{2}{*}{\multicolumn{15}{|c|}{ Waste Infrastructure }} \\
\hline $\mathrm{Cl}$ & \multirow{2}{*}{\multicolumn{15}{|c|}{$\begin{array}{c}\text { Clean lndex } \\
\text { Accumulation Rate }\end{array}$}} \\
\hline AR & & & & & & & & & & & & & & & \\
\hline $\mathrm{Al}$ & \multicolumn{15}{|c|}{ Accumulation Index } \\
\hline
\end{tabular}

\section{Design and Development of Waste Management Tool}

Once we had identified and selected critical KPIs (Section 3), we proceeded to design and develop an interactive Waste Management Tool suitable for education and informing policy. The concept was to create an application that can help students understand the challenges associated with waste management, and guide them through learning about KPIs that affect waste management systems' performance. Gamification elements make the experience more engaging, interactive, and pedagogically "sticky" to encourage concept retention. In order to design the tool, we used Unity Game Engine and we purchased relevant low-polygon count 3D objects from the Unity Asset Store to accelerate development. The game interface is described in the following subsections.

\subsection{Current Status of the Tool}

In its current form, the tool comprises a main menu (Figure 6) and a main scene (Figure 7). The main menu enables users to transition to main playable scene or alternatively allows the user to showcase the credits or exit the game.

The main scene is the interactive core of this application. It features an imaginary virtual city with population of 100,000 people that is comprised of nine areas laid out in a $3 \times 3$ matrix (Figure 7). Each area has unique and distinct parameters that may be randomly defined or tuned related to waste generation and management. When the main scene is loaded, the player camera moves from a close-up view to a top-down perspective to allow an overview of the entire city in a single window. From this top-down view, players are able to select and engage with the various interactive areas and elements of the city.

Upon loading the main scene, each area is automatically assigned with a random population number out of specific options. These options are 1500, 2000, 5000, 6500, 7000, $10,000,18,000,20,000$, and 30,000 to sum to 100,000 . The total population of 100,000 people helps to simplify calculations for the user. The graphics and the building models including 
houses do not reflect the numbers of the area population assigned but are representative and increase user engagement and relatability. In Figure 7, we see that the population of Area $_{11}$ was automatically set to 2000 people by the tool. The rest areas were assigned with each area having the value of one of the remaining choices from the options list.

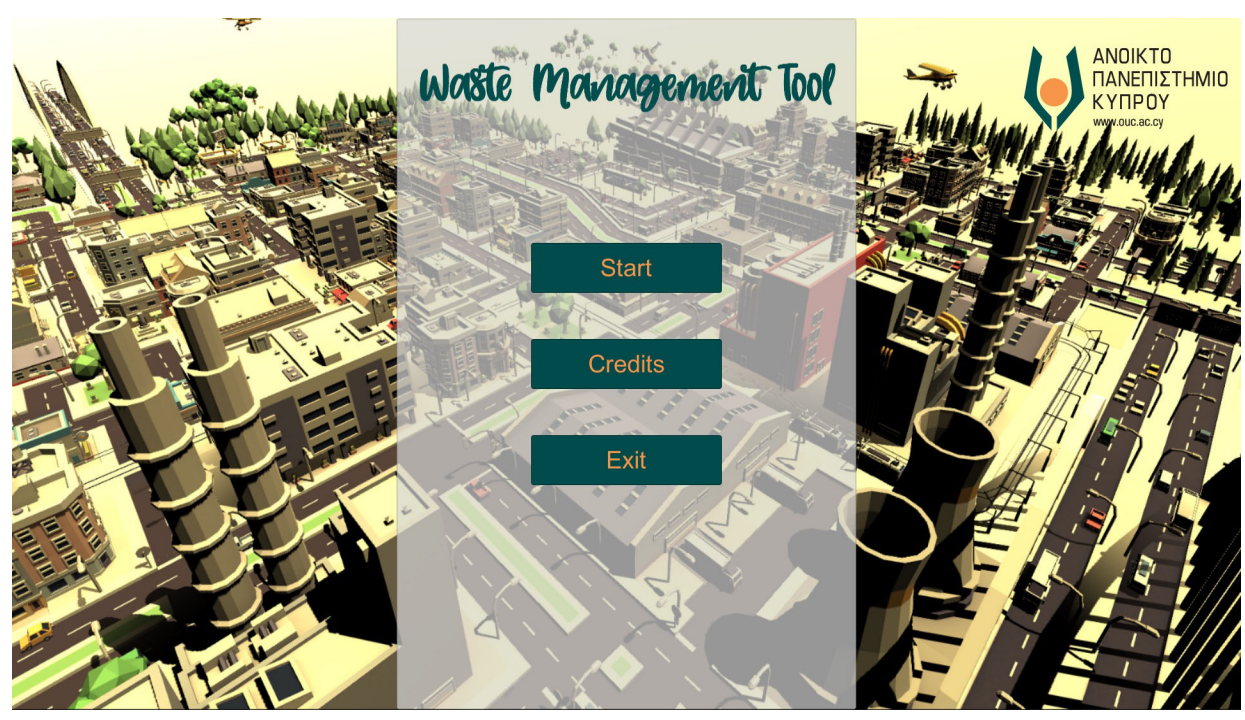

Figure 6. The Waste Management Tool's main menu allows players to start the simulator, view the credits, or exit the game.

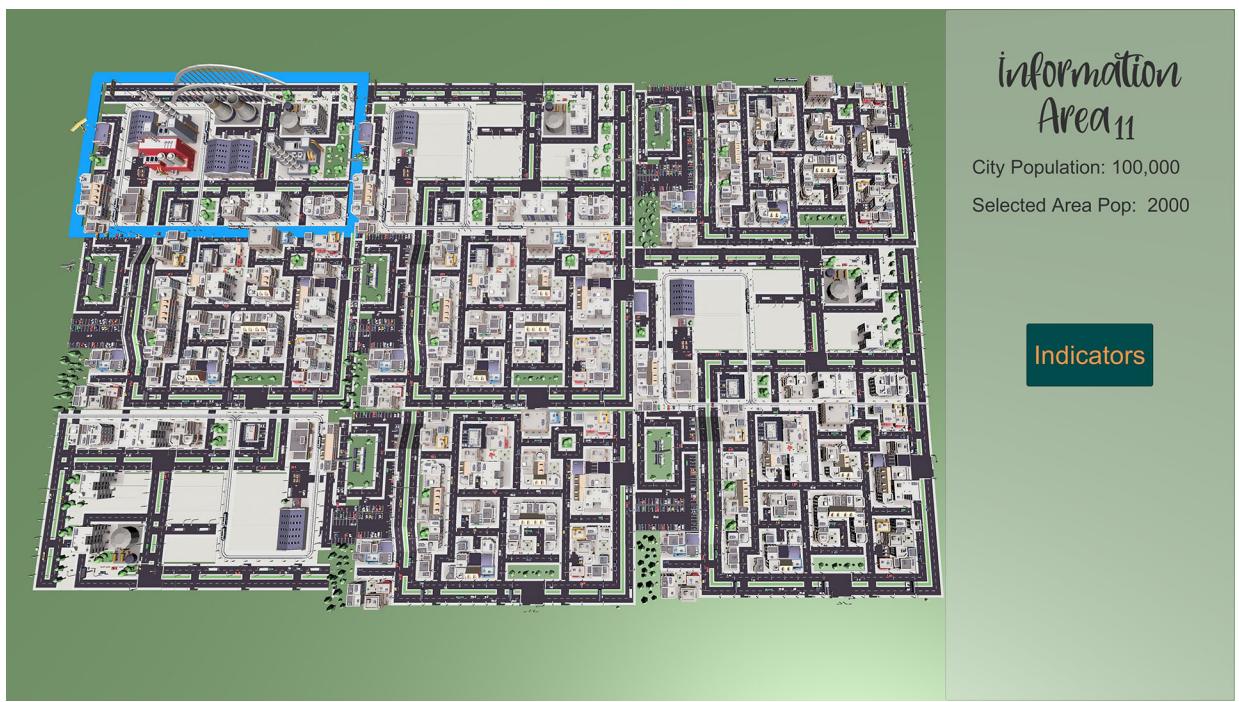

Figure 7. The Main Scene features a top-down view of the city, divided into nine parts. Each part can be highlighted, selected, and clicked to view information about waste management KPIs and policies in that region.

Having selected a specific area of the virtual city, the users may press the "Indicators" button on the right side of their screen. After doing so, a panel with the indicators (Figure 8) for the selected area appears. These indicators are the same KPIs that we have identified and presented in Section 3. 


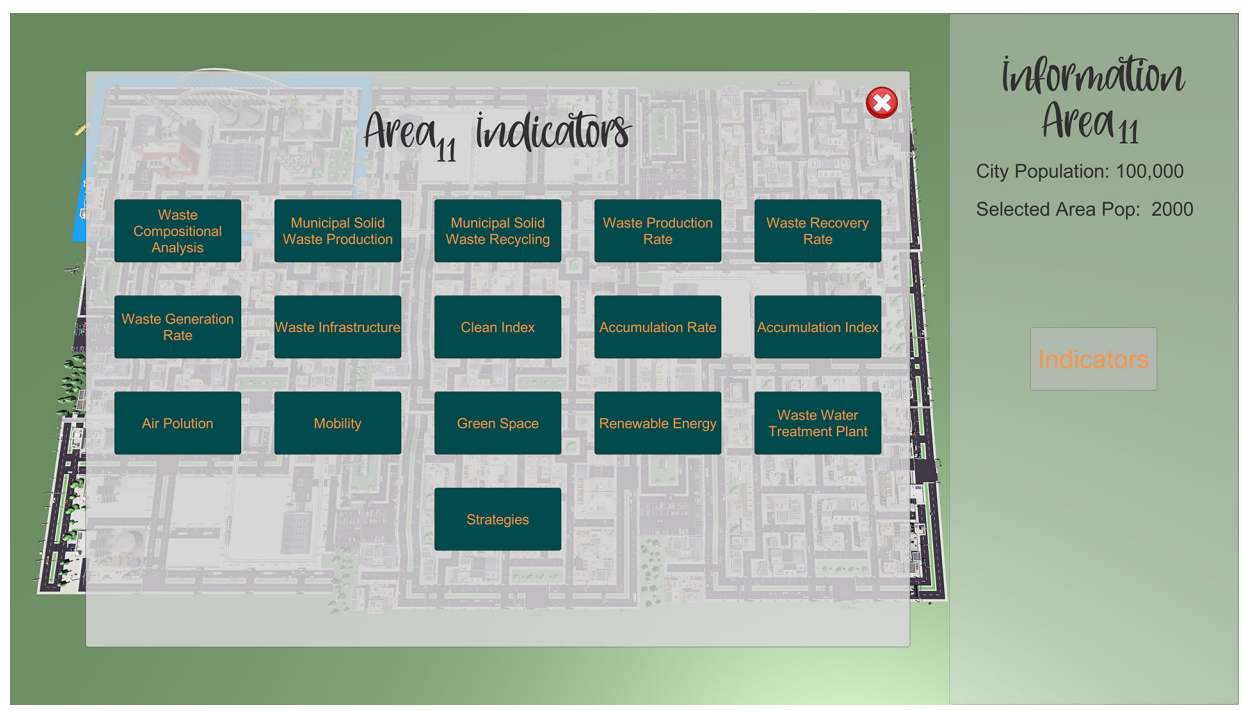

Figure 8. Key performance indicators for each region are shown on a dashboard to provide a high-level, easily interperable overview of waste management performance.

In this panel, the KPIs present new buttons that users can interact with. For illustrative purposes, we will explain how the first two indicators work. Starting with the Waste Compositional Analysis (MSW-C), this KPI is comprised of multiple configurable values each as described in Section 3.2.1. Using the amounts measured at Municipality of Paralimni and scaling up from 18,601 to 100,000 people for our simulator, we created Table 15 to display possible ranges in these categories for internal design purposes only. These amounts are scaled to fit each population option for all areas. The final bounds for each population option are presented in Table 16. These values are stored to an external and accessible file enabling easy customization in the case of new research developments necessitating specific game permutations.

Table 15. Waste Compositional Analysis categories for a population of 100,000 people and possible range in tn for each of the categories (figures per [13]). This table is used only for designing purposes and its amounts were later scaled to express the upper and lower bounds of each of the area population options.

\begin{tabular}{ccc}
\hline Categories of Waste & Scaled Est. Amount (tn) & Range (tn) \\
\hline PMD & 7639 & $5000-10,000$ \\
Plastic Film & 3588 & $2000-5000$ \\
Plastics Non-Recyclable & 1835 & $1000-3000$ \\
Aluminium/Ferrous & 682 & $500-1000$ \\
Paper & 8572 & $6000-10,000$ \\
Glass & 4327 & $3000-5000$ \\
Toilet and Kitchen Paper & 9652 & $8000-11,000$ \\
Food Waste (edible) & 12,055 & $10,000-14,000$ \\
Food Waste (inedible) & 4091 & $3000-5000$ \\
Organic Waste (Green Waste, Yard Waste) & 22,243 & $20,000-25,000$ \\
Others & 6494 & $5000-7000$ \\
\hline
\end{tabular}


Table 16. The Lower and Upper Bounds for each of the categories for all population options. These values were scaled based on the range from Table 15.

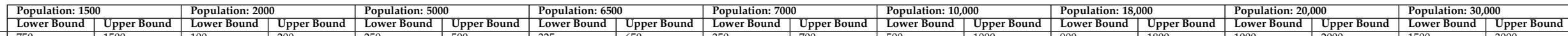

\begin{tabular}{|c|c|c|c|c|c|c|c|c|c|c|c|c|c|c|c|c|c|c|}
\hline & Lower bouna & Opper bouna & Lower bouna & Upper Dound & Lowe & Jppe & owe & $\overline{\mathrm{ppp}}$ & Douna & nd & id & ( & ind & opper & tome & Upper Bound & \begin{tabular}{|l|l|} 
Lower \\
1500
\end{tabular} & \\
\hline \begin{tabular}{|l|} 
PMD \\
Plastif Fim
\end{tabular} & 750 & 1500 & 100 & 200 & 250 & 500 & 325 & & & & & & & & & 2000 & 1500 & \\
\hline \begin{tabular}{|l|} 
Plastic Film \\
Plastic Non Recyclable \\
\end{tabular} & $\frac{300}{150}$ & 750 & $\frac{40}{20}$ & 100 & $\frac{100}{50}$ & 250 & $\frac{130}{65}$ & $\frac{325}{195}$ & 140 & $\frac{350}{210}$ & 200 & 500 & 360 & 900 & 400 & \begin{tabular}{|l|l|}
1000 \\
600
\end{tabular} & \begin{tabular}{|l|l|}
600 \\
300
\end{tabular} & $\frac{1500}{900}$ \\
\hline \begin{tabular}{|l} 
Aluminun/ Ferrous \\
\end{tabular} & 75 & 150 & 10 & 20 & 25 & 50 & 32 & 65 & 35 & 70 & 50 & 100 & 90 & $\begin{array}{l}350 \\
180\end{array}$ & 100 & \begin{tabular}{|l|}
2000 \\
200
\end{tabular} & \begin{tabular}{|l|l|}
500 \\
150
\end{tabular} & 300 \\
\hline \begin{tabular}{|l|l|} 
Paper \\
\end{tabular} & 900 & 1500 & 120 & 200 & 300 & 500 & 390 & 650 & 420 & 700 & 600 & 1000 & 1080 & 1800 & 1200 & 2000 & 1800 & 3000 \\
\hline \begin{tabular}{|l|} 
Glass \\
\end{tabular} & 450 & 750 & 60 & 100 & 150 & 250 & 195 & 325 & 210 & 350 & 300 & 500 & 540 & 900 & 600 & 1000 & 900 & 1500 \\
\hline \begin{tabular}{|l} 
Toilet and Kitchen paper \\
\end{tabular} & 1200 & 1650 & 160 & 220 & 400 & 550 & 520 & 715 & 560 & 770 & 800 & 1100 & 1440 & $\begin{array}{l}1980 \\
5200\end{array}$ & 1600 & \begin{tabular}{|l|l|}
2200 \\
\end{tabular} & \begin{tabular}{|l|l|}
2400 \\
300
\end{tabular} & $\frac{3300}{4200}$ \\
\hline \begin{tabular}{|l} 
Food Waste Edible \\
Food Waste Inedible
\end{tabular} & $\frac{1500}{450}$ & 2100 & 200 & $\frac{280}{100}$ & $\frac{500}{150}$ & $\begin{array}{l}700 \\
250\end{array}$ & $\frac{650}{195}$ & \begin{tabular}{|l|l|}
910 \\
325
\end{tabular} & 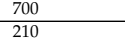 & $\frac{980}{350}$ & $\frac{1000}{300}$ & $\begin{array}{l}\frac{1400}{5000} \\
\end{array}$ & $\frac{1800}{540}$ & $\frac{2520}{900}$ & $\frac{2000}{600}$ & \begin{tabular}{|l|}
2800 \\
1000 \\
\end{tabular} & \begin{tabular}{|l|l}
3000 \\
900
\end{tabular} & $\begin{array}{l}4200 \\
1500\end{array}$ \\
\hline \begin{tabular}{|l} 
Organic Waste \\
\end{tabular} & 3000 & 3750 & 400 & 500 & 1000 & 1250 & 1300 & 1625 & 1400 & 1750 & 2000 & 2500 & 3600 & 4500 & 4000 & 5000 & 6000 & 7500 \\
\hline \begin{tabular}{|l|} 
Others \\
\end{tabular} & 750 & 1050 & 100 & 140 & 250 & 350 & 325 & \begin{tabular}{|l|l|l|l|l}
455 & \\
\end{tabular} & 350 & & 500 & 700 & & $\begin{array}{ll}1260 \\
\end{array}$ & 1000 & 1400 & 1500 & 2100 \\
\hline
\end{tabular}


Similar to the area populations, the tool automatically loads the lower and upper bounds for the relevant population number. At the same time, it randomly sets a new value in the respective sliders for each category, creating a unique but broadly-similar city waste footprint for each user. A representative example for $A r e a_{11}$ is showcased in Figure 9. Users may then choose to change these values.

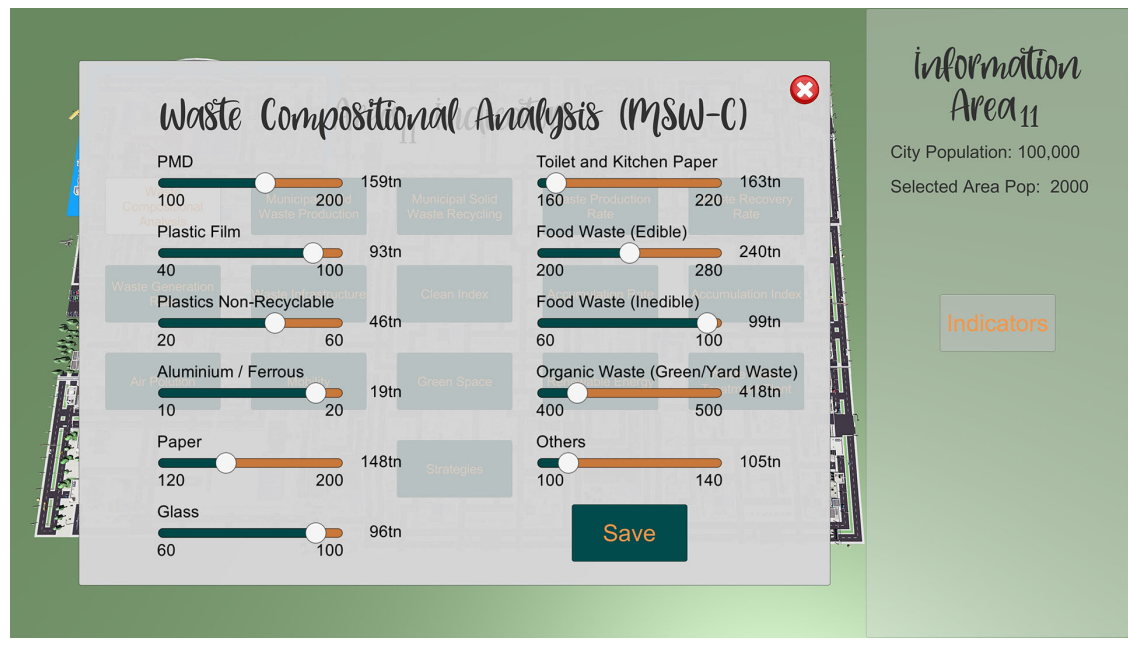

Figure 9. Each area's waste generation and policy parameters can be altered independently.

Next, we have the Municipal Solid Waste Production KPI (MSW-P). This KPI does not have any user-configurable categories and is completely independent of MSW-C. This value comes from the division of the total amount of waste divided by the population of the area, as shown in Equation (4).

Based on the tool's randomly-generated amounts (Figure 9) and the population of Area $_{11}$, (2000), we have the following:

$$
\frac{Q_{\text {Tot }}(t)}{Q_{P O P}(t)}=\frac{159+93+46+19+148+96+163+240+99+418+105}{2000}=0.793
$$

As we notice in Figure 10, the result is the same as the calculated one in Equation (15). This result can change in real time when a slider value from MSW-C panel is also changed.

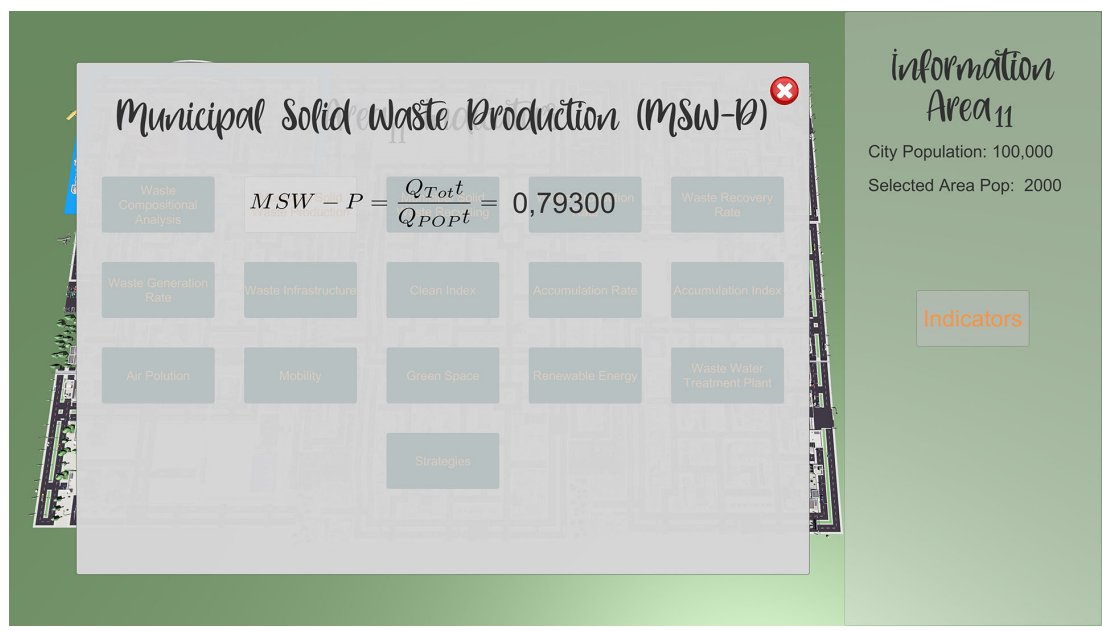

Figure 10. Clicking each metric provides information about how it is calculated, which helps students learn to create effective management policies. These indicators reflect the parameters as identified in Section 3 (note that due to regional differences, the figure shows a comma rather than a period in the numeric text). 
These examples are representative of how all models involved in the computation of waste production and management are handled in the game design.

Using these indicators, along with configurable elements thereof, allows individuals to use the game as a means of modelling waste generation and management. Through study and play, users may learn those metrics most affecting waste production and mitigation in order to inform effective policies for diverse scenarios.

With the game created and reflecting the model developed in Section 3, this tool will be used to enable a range of academic studies that will be the subject of future work. Ongoing work will conduct playtesting with diverse constituents, the feedback from which will be fed into a version of the game to be made freely available to researchers (please contact the authors for additional information).

\section{Conclusions and Future Work}

Waste management is a critical and growing challenge, particularly in urban environments. Observational data are some of the best ways to study waste management to devise effective policy and to raise individual awareness that may curb waste production. Existing tools are either oversimplified or too complex for individuals to pick up and play, so we developed a game meeting the opportunity of joining a robust multi-factor waste generation and management model with ease of use and clear, rapid feedback to users. In this educationally-focused tool [64-66], students and policymakers may engage with the waste chain of a virtual city, changing model parameters and observing their affect on waste management performance through the use of visible key performance indicators. The game itself is built upon a robustly-defined multi-criteria decision-making problem comprising multiple variables.

Compared with existing modelling approaches that either oversimplify or require complex setup and deep domain knowledge, this game is a "Pareto optimal" solution. It is a highly-detailed real-world planning tool that also does an excellent job relative to the effort involved in setting up and running the simulation. From easy-to-make changes and readily-visible indicators, the broad impact of generation and policy changes is clearly understood. Enhanced knowledge stemming from gameplay may therefore contribute towards the creation of enhanced social policies and constituent engagement in efforts to reduce and manage waste. Particularly, participants will leave playing the game having a better understanding of the challenges associated with waste management with gamifying elements such as clearly presented and easy-to-track KPIs making the experience memorable and enduring.

While today, waste data are simulated, future virtual cities may instead make use of real-world data from municipalities and other government agencies in real time using IoT [67] to showcase examples of effective-and suboptimal—performance.

The designed tool may be integrated with other game-based simulators $[68,69]$ to help quantify and seek to reduce other negative externalities, such as vehicle emissions, using real-world automotive diagnostic data and solutions [70-72]. Real-world fault data may also be captured from mobile devices [73-79] as a means of informing simulation of fuel-wasting faults such that the transit planning strategies reflect true inefficiencies, while a broader game might even model how waste bin placement might impact pedestrian traffic [80] and efficiently mirror cities digitally and in real time [81]. Even industrial processes $[82,83]$ may be mirrored with the aim of improving resource efficiency and reducing waste. In the consumer-facing world, there may be opportunities to mitigate significant healthcare and home-life related waste, for example by integrating gameified waste modelling with digitally-connected disposable smart devices such as diapers [84] to track and trace the true chain of custody and provenance of real-world waste.

Author Contributions: Conceptualization, G.P., A.Z. and K.P.; methodology, G.P., I.P. and A.Z.; investigation, J.R. and I.P.; writing — original draft preparation, I.P., J.E.S., J.R., G.P. and K.P.; writingreview and editing, G.P., J.E.S., A.Z. and K.P.; visualization, G.P.; supervision, G.P., A.Z. and J.E.S.; 
project administration, G.P., A.Z. and J.E.S. All authors have read and agreed to the published version of the manuscript.

Funding: There was no external funding provided for this research.

Institutional Review Board Statement: Not applicable.

Informed Consent Statement: Not applicable.

Data Availability Statement: Not applicable.

Conflicts of Interest: The authors declare no known conflict of interest.

\section{References}

1. Ackerman, F. Waste management and climate change. Local Environ. 2000, 5, 223-229. [CrossRef]

2. Seeberger, J.; Grandhi, R.; Kim, S.S.; Mase, W.A.; Reponen, T.; Ho, S.m.; Chen, A. Special report: E-waste management in the united states and public health implications. J. Environ. Health 2016, 79, 8-17. [PubMed]

3. Haupt, T.; Arnold, U.; Bidlingmaier, W. Studien-und Hochschulübergreifender Einsatz Einer Engl.-spr. Multimedialen Urban Infrastructure Development Simulation in der Akademischen Ausund Weiterbildung-MUrIDS (Cross-Study and Cross-University Use of an English Multimedia Urban Infrastructure Deve. Workshop: Multimedia in Bildung und Wirtschaft-Einsatz und Nachhaltigkeit von eLearning, Volume 22, p. 5. Available online: https:/ /his-he.de/fileadmin/user_upload/Publikationen/Pro jektberichte_alte_Website/Hochschulplanung/hp165.pdf (accessed on 24 October 2021).

4. Arnold, U.; Söbke, H.; Reichelt, M. Simcity in infrastructure management education. Educ. Sci. 2019, 9, 209. [CrossRef]

5. Fernández, P.; Ceacero-Moreno, M. Urban sustainability and natural hazards management; designs using simulations. Sustainability 2021, 13, 649. [CrossRef]

6. Wu, K.C.; Huang, P.Y. Treatment of an Anonymous Recipient: Solid-Waste Management Simulation Game. J. Educ. Comput. Res. 2015, 52, 568-600. [CrossRef]

7. Lepe-Salazar, F.; Cortés-Álvarez, T.; Serratos-Chávez, E.; Jáuregui-Flores, L.; Juárez-Cervantes, E.; Valdovinos-López, R.; RincónMartínez, D.; la Madrid, R. A Game-Based Service to Mitigate the Risk of Inundations Caused by Solid Waste Accumulation. In Making Smart Cities More Playable: Exploring Playable Cities; Nijholt, A., Ed.; Springer: Singapore, 2020; pp. 279-299. [CrossRef]

8. Wilensky, U. NetLogo. 1999. Available online: http:/ / ccl.northwestern.edu/netlogo/ (accessed on 24 October 2021).

9. de Souza, V.M.; Bloemhof, J.; Borsato, M. Assessing the eco-effectiveness of a solid waste management plan using agent-based modelling. Waste Manag. 2021, 125, 235-248. [CrossRef]

10. Likotiko, E.; Nyambo, D.; Mwangoka, J. Multi-Agent Based IoT Smart Waste Monitoring and Collection Architecture. Int. J. Comput. Sci. Eng. Inf. Technol. 2017, 7, 1-14. [CrossRef]

11. European Commission. Green City Accord Target Areas. 2021. Available online: https://ec.europa.eu/environment/green-cityaccord/monitoring-framework_en (accessed on 24 October 2021).

12. Loizia, P.; Voukkali, I.; Zorpas, A.A.; Navarro Pedreño, J.; Chatziparaskeva, G.; Inglezakis, V.J.; Vardopoulos, I.; Doula, M. Measuring the level of environmental performance in insular areas, through key performed indicators, in the framework of waste strategy development. Sci. Total Environ. 2021, 753, 141974. [CrossRef]

13. Zorpas, A.A.; Lasaridi, K.; Voukkali, I.; Loizia, P.; Chroni, C. Household waste compositional analysis variation from insular communities in the framework of waste prevention strategy plans. Waste Manag. 2015, 38, 3-11. [CrossRef]

14. Zorpas, A.A.; Lasaridi, K.; Voukkali, I.; Loizia, P.; Chroni, C. Promoting Sustainable Waste Prevention Strategy Activities and Planning in Relation to the Waste Framework Directive in Insular Communities. Environ. Process. 2015, 2, 159-173. [CrossRef]

15. Voukkali, I.; Loizia, P.; Navarro-Pedreño, J.; Zorpas, A.A. Urban strategies evaluation for waste management in coastal areas in the framework of area metabolism. Waste Manag. Res. J. Sustain. Circ. Econ. 2021, 39, 0734242X20972773. [CrossRef]

16. Zorpas, A.A. Strategy development in the framework of waste management. Sci. Total Environ. 2020, 716, 137088. [CrossRef]

17. Sharp, V.; Giorgi, S.; Wilson, D.C. Methods to monitor and evaluate household waste prevention. Waste Manag. Res. 2010, 28, 269-280. [CrossRef]

18. Vardopoulos, I.; Konstantopoulos, I.; Zorpas, A.A.; Limousy, L.; Bennici, S.; Inglezakis, V.J.; Voukkali, I. Sustainable metropolitan areas perspectives through assessment of the existing waste management strategies. Environ. Sci. Pollut. Res. 2021, 28, 24305-24320. [CrossRef] [PubMed]

19. Victor, P.A. Indicators of sustainable development: Some lessons from capital theory. Ecol. Econ. 1991, 4, 191-213. [CrossRef]

20. Green Dot Cyprus. Green National Household Results per Municipality per Year Cyprus. 2011. Available online: https: / / greendot.com.cy/en/ (accessed on 24 October 2021).

21. The European Parliament and the Council of the European Union. Directive 2003/35/EC of the European Parliament and of the Council of 26 May 2003 providing for public participation in respect of the drawing up of certain plans and programmes relating to the environment and amending with regard to public participation. Off. J. Eur. Union 2003, 17-25.

22. Printing Office of the Republic of Cyprus. Packaging and Waste Packaging (Amendment) Law; (Law No. 159(I)/2005); Printing Office of the Republic of Cyprus: Nicosia, Cyprus, 2005. 
23. Rhyner, C.; Schwartz, L.; Wenger, R.; Kohrell, M. Waste Management and Resource Recovery; CRC Press: Boca Raton, FL, USA, 2017; pp. 1-528. [CrossRef]

24. Luttenberger, L.R. Waste management challenges in transition to circular economy-Case of Croatia. J. Clean. Prod. 2020, 256, 120495. 2020.120495. [CrossRef]

25. Bhada-Tata, P.; Hoornweg, D. What a Waste?: A Global Review of Solid Waste Management. 2012. Available online: http: // hdl.handle.net/10986/17388 (accessed on 24 October 2021).

26. Kaza, S.; Yao, L.; Bhada-Tata, P.; Van Woerden, F. What a Waste 2.0: A Global Snapshot of Solid Waste Management to 2050; The World Bank: Washington, DC, USA, 2018; p. 292. [CrossRef]

27. Alkalay, R.; Pasternak, G.; Zask, A. Clean-coast index-A new approach for beach cleanliness assessment. Ocean. Coast. Manag. 2007, 50, 352-362. [CrossRef]

28. Messineo, A.; Panno, D. Municipal waste management in Sicily: Practices and challenges. Waste Manag. 2008, 28, 1201-1208. [CrossRef]

29. Loizia, P.; Voukkali, I.; Chatziparaskeva, G.; Navarro-Pedreño, J.; Zorpas, A.A. Measuring the Level of Environmental Performance on Coastal Environment before and during the COVID-19 Pandemic: A Case Study from Cyprus. Sustainability 2021, $12,2485$. [CrossRef]

30. Ghorani azam, A.; Riahi-Zanjani, B.; Balali-Mood, M. Effects of air pollution on human health and practical measures for prevention in Iran. J. Res. Med. Sci. 2016, 21, 65. [CrossRef]

31. Zarate, E. Understanding the Origins and Fate of Air Pollution in Bogotá, Colombia. 2007. Available online: https://infoscience. epfl.ch/record/100037 (accessed on 24 October 2021).

32. Ho, B. Urban Air Pollution; IntechOpen: Rijeka, Croatia, 2012. [CrossRef]

33. Hogg, D.; Ballinger, A. The Potential Contribution of Waste Management to a Low Carbon Economy; Eunomia Research \& Consulting Ltd.: Bristol, UK, 2015.

34. Department of Labour Inspection (DLI) of the Ministry of Labour; Insurance, S. Air Quality in Cyprus. Available online: https:/ / www.airquality.dli.mlsi.gov.cy/ (accessed on 24 October 2021).

35. Pisoni, E.; Christidis, P.; Thunis, P.; Trombetti, M. Evaluating the impact of "Sustainable Urban Mobility Plans" on urban background air quality. J. Environ. Manag. 2019, 231, 249-255. [CrossRef]

36. Kasten, P.; Bracker, J.; Haller, M.; Purwanto, J. Assessing the Status of Electrification of the Road Transport Passenger Vehicles and Potential Future Implications for the Environment and European Energy System; Öko-Institut: Darmstadt, Germany, 2016.

37. De la Barrera, F.; Reyes-Paecke, S.; Banzhaf, E. Indicators for green spaces in contrasting urban settings. Ecol. Indic. 2016, 62, 212-219. [CrossRef]

38. Gerstenberg, T.; Hofmann, M. Perception and preference of trees: A psychological contribution to tree species selection in urban areas. Urban For. Urban Green. 2015, 15, 103-111. [CrossRef]

39. European Commission. Building a Green Infrastructure for Europe; Publications Office of the European Union: Luxembourg; Brussels, Belgium, 2013; p. 22. [CrossRef]

40. World Health Organisation(WHO). Health Indicators of Sustainable Cities in the Context of the Rio+20 UN Conference on Sustainable Development; WHO: Geneva, Switzerland, 2012.

41. Russo, A.; Cirella, G. Modern Compact Cities: How Much Greenery Do We Need? Int. J. Environ. Res. Public Health 2018, 15, 2180. [CrossRef] [PubMed]

42. Delponte, I.; Schenone, C. RES Implementation in Urban Areas: An Updated Overview. Sustainability 2020, 12, 382. [CrossRef]

43. European Commission. Resolution of the European Committee of the Regions-The Green Deal in partnership with local and regional authorities. In Communication from the Commission to the European Parliament, The European Council, The Council, The European Economic and Social Committee and the Committee of the Regions the European Green Deal; Number COM(2019) 640 Final; European Commission: Brussels, Belgium; Luxembourg, 2019; p. 24.

44. Zorpas, A.A.; Saranti, A. Multi-criteria analysis of sustainable environmental clean technologies for the treatment of winery's wastewater. Int. J. Glob. Environ. Issues 2016, 15, 151-168. [CrossRef]

45. Cyprus, T.S.O. Transmission System Operator Cyprus. 2020. Available online: https://tsoc.org.cy/electrical-system/energy-gen eration-records/res-penetration/ (accessed on 24 October 2021).

46. Regu, C.E. Cyprus Energy Regulatory Authority. 2021. Available online: https://www.cera.org.cy/en-gb/smv/sp-graph (accessed on 24 October 2021).

47. Republic of Cyprus, Statistical Service, Ministry of Finance. Demographic Statistics 2019. 2019. Available online: https://www.mof.gov.cy/mof/cystat/statistics.nsf/populationcondition_21main_en/populationcondition_21main_en ?OpenForm\&sub=1\&sel=1 (accessed on 24 October 2021).

48. European Commission. Directive (EU) 2018/2001 of the European Parliament and of the Council of 11 December 2018 on the Promotion of the Use of Energy from Renewable Sources (Recast) (Text with EEA Relevance)Text with EEA Relevance; Technical Report; European Commission: Brussels, Belgium; Luxembourg, 2018.

49. Pesqueira, J.F.J.R.; Pereira, M.F.R.; Silva, A.M.T. Environmental impact assessment of advanced urban wastewater treatment technologies for the removal of priority substances and contaminants of emerging concern: A review. J. Clean. Prod. 2020, 261, 121078. [CrossRef] 
50. European Commission. Communication from the Commission to the European Parliament, the Council, the European Economic and Social Committee and the Committee of the Regions A Policy Framework for Climate and Energy in the Period from 2020 to 2030; European Commission: Brussels, Belgium; Luxembourg, 2014.

51. European Commission. Report from the Commission to the European Parliament, the Council, the European Economic and Social Committee and the Committee of the Regions- Tenth Report on the Implementation Status and Programmes for Implementation (as required by Article 17 of Coun; European Commission: Brussels, Belgium; Luxembourg, 2016.

52. World Health Organisation(WHO). Population Connected to Wastewater Treatment Facilities. 2015. Available online: https: //gateway.euro.who.int/en/indicators/enhis_4-population-connected-to-wastewater-treatment-facilities/ (accessed on 24 October 2021).

53. Eurostat. Population Connected to Wastewater Treatment Plants. 2018. Available online: http://appsso.eurostat.ec.europa.eu/n ui/show.do?dataset=env_ww_con\&lang=en (accessed on 24 October 2021).

54. Niccolucci, V.; Botto, S.; Rugani, B.; Nicolardi, V.; Bastianoni, S.; Gaggi, C. The real water consumption behind drinking water: The case of Italy. J. Environ. Manag. 2011, 92, 2611-2618. [CrossRef]

55. European Commission. Communication from the Commission to the European Parliament, the Council, the European Economic and Social Committee and the Committee of the Regions Closing the Loop-An EU Action Plan for the Circular Economy; Number COM(2015) 614 Final; European Commission: Brussels, Belgium; Luxembourg, 2015.

56. Nations, U. Transforming Our World: The 2030 Agenda for Sustainable Development. 2015. Available online: https://sdgs.un.or g/2030agenda (accessed on 24 October 2021).

57. Mohanty, S. Everything You Wanted to Know About Smart Cities. IEEE Consum. Electron. Mag. 2016, 5, 60-70. [CrossRef]

58. Stambouli, A.B.; Khiat, Z.; Flazi, S.; Kitamura, Y. A review on the renewable energy development in Algeria: Current perspective, energy scenario and sustainability issues. Renew. Sustain. Energy Rev. 2012, 16, 4445-4460. [CrossRef]

59. Petinrin, J.O.; Shaaban, M. Renewable energy for continuous energy sustainability in Malaysia. Renew. Sustain. Energy Rev. 2015, 50, 967-981. [CrossRef]

60. Calisto Friant, M.; Vermeulen, W.J.V.; Salomone, R. Analysing European Union circular economy policies: Words versus actions. Sustain. Prod. Consum. 2021, 27, 337-353. [CrossRef]

61. Wittmaier, M.; Langer, S.; Sawilla, B. Possibilities and limitations of life cycle assessment (LCA) in the development of waste utilization systems-Applied examples for a region in Northern Germany. Waste Manag. 2009, 29, 1732-1738. [CrossRef]

62. Brook Lyndhurst. WR1204 Household Waste Prevention Evidence Review: L1 m1-Executive Report, a Report for Defra's Waste and Resources Evidence Programme; Technical Report; Brook Lyndhurst: London, UK, 2009.

63. Shi, Y.; Ge, X.; Yuan, X.; Wang, Q.; Kellett, J.; Li, F.; Ba, K. An Integrated Indicator System and Evaluation Model for Regional Sustainable Development. Sustainability 2019, 11, 2183. [CrossRef]

64. Strzebkowski, R.; Gehrmann, T.; Siegel, J.E.; Politopoulos, K.; Christodoulides, C.; Pappas, G. AR/VR/Game-based Edutainment Applications and Real-Time Data Visualisation Technologies for Discovery Learning in the Industry and Distance Education; OEB: Berlin, Germany, 2018.

65. Avraamidou, A.; Lambis, S.; Pappas, G.; Christodoulides, C. Enhancing Distance Education Students' Learning Experience Through Emerging Technologies. In Proceedings of the INTED2019 Proceedings, Valencia, Spain, 11-13 March 2019; Volume 1, pp. 3022-3029. [CrossRef]

66. Pappas, G.; Peratikou, P.; Siegel, J.E.; Politopoulos, K.; Christodoulides, C.; Stavrou, S. Cyber Escape Room: An educational $3 \mathrm{D}$ escape room game within a cyber range training realm. In Proceedings of the INTED2020 Proceedings, 14th International Technology, Education and Development Conference, Valencia, Spain, 2-4 March 2020; pp. 2621-2627. [CrossRef]

67. Pappas, G.; Siegel, J.E.; Vogiatzakis, I.; Politopoulos, K. Gamification and the Internet of Things in Education. In Handbook of Intelligent Techniques in Educational Process; Springer: Berlin/Heidelberg, Germany, 2022.

68. Pappas, G.; Siegel, J.E.; Politopoulos, K. VirtualCar: Virtual Mirroring of IoT-Enabled Avacars in AR, VR and Desktop Applications. 2018. Available online: https:/ / diglib.eg.org/handle/10.2312/egve20181381 (accessed on 24 October 2021).

69. Pappas, G.; Siegel, J.E.; Politopoulos, K.; Sun, Y. A Gamified Simulator and Physical Platform for Self-Driving Algorithm Training and Validation. Electronics 2021, 10, 1112. [CrossRef]

70. Siegel, J.E. Cloudthink and the Avacar: Embedded Design to Create Virtual Vehicles for Cloud-Based Informatics, Telematics, and Infotainment. S.M. Thesis, Massachusetts Institute of Technology, Cambridge, MA, USA, 2013.

71. Wilhelm, E.; Siegel, J.E.; Mayer, S.; Sadamori, L.; Dsouza, S.; Chau, C.K.; Sarma, S.E. Cloudthink: A scalable secure platform for mirroring transportation systems in the cloud. Transport 2015, 30, 320-329. [CrossRef]

72. Siegel, J.E. Data Proxies, the Cognitive Layer, and Application Locality: Enablers of Cloud-Connected Vehicles and Next,Generation Internet of Things. Ph.D. Thesis, Massachusetts Institute of Technology, Cambridge, MA, USA, 2016.

73. Siegel, J.E.; Bhattacharyya, R.; Deshpande, A.; Sarma, S.E. Vehicular engine oil service life characterization using on-board diagnostic (OBD) sensor data. In Proceedings of the IEEE Sensors 2014, Valencia, Spain, 2-5 November 2014; pp. $1722-1725$.

74. Siegel, J.E.; Bhattacharyya, R.; Deshpande, A.; Sarma, S.E. Smartphone-Based Wheel Imbalance Detection. In Proceedings of the Dynamic Systems and Control Conference, Columbus, OH, USA, 28-30 October 2015.

75. Siegel, J.E.; Kumar, S.; Ehrenberg, I.; Sarma, S.E. Engine misfire detection with pervasive mobile audio. In Proceedings of the Joint European Conference on Machine Learning and Knowledge Discovery in Databases, Riva del Garda, Italy, 19-23 September 2016; Springer: Cham, Switzerland, 2016; pp. 226-241. 
76. Siegel, J.E.; Bhattacharyya, R.; Deshpande, A.; Sarma, S.E. Smartphone-Based Vehicular Tire Pressure and Condition Monitoring. In Proceedings of the SAI Intelligent Systems Conference, London, UK, 21-22 September 2016; pp. 446-455.

77. Siegel, J.E.; Bhattacharyya, R.; Kumar, S.; Sarma, S.E. Air filter particulate loading detection using smartphone audio and optimized ensemble classification. Eng. Appl. Artif. Intell. 2017, 66, 104-112. [CrossRef]

78. Siegel, J.E.; Sun, Y.; Sarma, S.E. Automotive Diagnostics as a Service: An Artificially Intelligent Mobile Application for Tire Condition Assessment. In Proceedings of the International Conference on AI and Mobile Services, Seattle, WA, USA, 2530 June 2018.

79. Siegel, J.E.; Coda, U.; Terwilliger, A. Surveying Off-Board and Extra-Vehicular Monitoring and Progress Towards Pervasive Diagnostics. arXiv 2021, arXiv:2007.03759.

80. Pappas, G.; Siegel, J.E.; Rutkowski, J.; Schaaf, A. Game and Simulation Design for Studying Pedestrian-Automated Vehicle Interactions. arXiv 2021, arXiv:2109.15205.

81. Siegel, J.E.; Kumar, S.; Sarma, S.E. The Future Internet of Things: Secure, Efficient, and Model-Based. IEEE Internet Things J. 2017, 5, 2386-2398. [CrossRef]

82. Kumaravel, B.T.; Bhattacharyya, R.; Siegel, J.E.; Sarma, S.E.; Arunachalam, N. Development of an Internet of Things enabled manufacturing system for tool wear characterization. In Proceedings of the 2017 IEEE 3rd International Symposium in Robotics and Manufacturing Automation (ROMA), Kuala Lumpur, Malaysia, 19-21 September 2017; pp. 1-6.

83. Siegel, J.E.; Beemer, M.F.; Shepard, S.M. Automated non-destructive inspection of fused filament fabrication components using thermographic signal reconstruction. Addit. Manuf. 2020, 31, 100923. [CrossRef]

84. Sen, P.; Kantareddy, S.N.R.; Bhattacharyya, R.; Sarma, S.E.; Siegel, J.E. Low-cost diaper wetness detection using hydrogel-based RFID tags. IEEE Sens. J. 2020, 20, 3293-3302. [CrossRef] 